\title{
MEMORANDUM
}

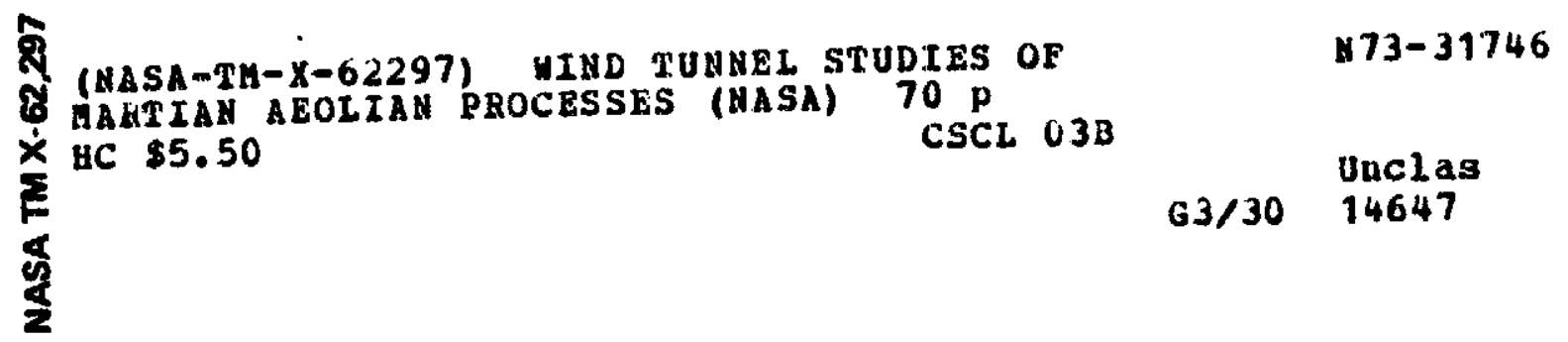

WIND TUNNEL STUDIF: OF MARTIAN AEOLIAN PROCESSES

Ronald Greeley, James D. Iversen, James B. Pollack,

Nancy Udovich, and Bruce White

University of Santa Clara

Santa Clara, Calif. 95053

Lowa State University

Ames, lowa 50010

and

Ames Research Center

Moffett Field, Calif. 94035

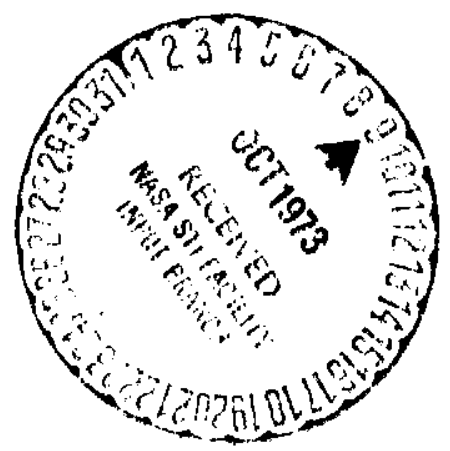

May 1973 


\title{
WIND TUNNEL STUDIES OF MARTIAN
}

\section{AEOLIAN PROCESSES}

\author{
Ronald Greeley ${ }^{1}$ \\ James D. Iversen ${ }^{2}$ \\ James B. Pollack ${ }^{3}$ \\ Nancy Udovich ${ }^{1}$ \\ Bruce White 2
}

1 Physics Department, Untversity of Santa Clara, Cal1f. 95053 (Mall Address: Space Sctence Division, Ames Research Center, National Aeronautics and Space Administration, Moffett Fleld, Calif. 94035)

2 Department of Aerospace Fnglneering, Iowa State UnIverstty Ames, towa 50010

${ }^{3}$ Space Sclences D1vlsion, Ames Research Center National Aeronautics and Space Admintstration, Moffet Field, Calif. 94035 


\section{ABSTRACT}

In order to determine the nature of martian aeolian processes, an investigation is in progress which in:olves wind tunnel simulations, geologic fleld studies, theoretical model studies, and analyses of Mariner 9 imagery; this report presents the preliminary $r \cdot s i l t s$. Threshold speed experiments were conducted for particles ranging in specific gravity from 1.3 to 11.35 and diameter from $10.2 \mu$ to $1290 \mu$ to verify and better define Bagncld's (10:1) expressions fox grain movement, particularly for low particle Reynolds numbers and to study the effects of aerodynamic lift and surface roughness. Wind tunnel simulations were conducted to determine the flow field over raised rim craters and associated zones of deposition and erosion. A horseshoe vortex forms around the crater, resulting in two axial velocity maxima in the lee of the crater which cause a zone of preferential erosion in the wake of the crater. Reverse flow direction occurs on the floor of the crater. The result is a distinct pattern of erosion and deposition which Is similax to some martian craters and which indicates that some dark zones around martian craters are exostonal and some $11 \mathrm{ght}$ zones are depositional. Analyses of the erosional and depositional zones associated wth a $6 \mathrm{~m}$ ratsed rim crater on an open field and a $1.2 \mathrm{~km}$ natural impact crater ititatively confirm the wind tunnel results.

Application of the wind tunnel results to Mars Indicates that for flat surfaces, free stream winds in excess of $400 \mathrm{~km} / \mathrm{hr}$ are required for grain movement. However, lower velocities would be required in reglons of $h \mathrm{gh}$ surface roughness, e.8., cratered terratn, and it ts proposed that such 
reglone could be zones of origin for some martian dust storms. Anslysis of the Corlolis effect on surface stress shows that surface streaks would be deflected about $15^{\circ}$ from the geostrophic wind direction at mid-latitudes. 
Dust storms and other aeolian activities have been suspected to occur on Mars on the basis of telescoptc observations (deVaucoulers, 1954; Kufper, 1957; Rea, 1964; and others) and iheoretical considerations of the martian surface and atmosphere (Ryan, 1964; Sagan and Pollack, 1969). Mariner 9 results confins the existence of aeolian features on Mars and show that acollan processes play a significant role in modtfying the martian surface (Sagan et al., 1973). Many aeolian features were observed in vartous stages of formation 88 the martian dust storm of 1971-1972 slowly subsided (Sagan et a.., 1972). Analyses of Mariner 9 inagery revesi many features that appear to have resulted from long-term aeolian processes (Masursky, 1973). Knowledge of martian aeolian activity as a geologic process is essential to the understanding of the complex surface characteristics and geologic history of the planet.

Martian deolian features occur in a yariety of forms, most of which are associated with craters or other topographic obstructions. The features are subdivided into two general types: dark streaks and light streaks (figures 1 and 2). During the Mariner 9 mission, several areas were imaged repetitively in order to observe possible surface changes. Figure 1 shows a crater $17 \mathrm{~km}$ in diameter that developed a dark fan-shaped streak within a 38 day pertod (Sagan et al., 1972); it 1s typical of many dark features. Figure 2 shuws 1ight streaks assnctated with craters. These and all 11ght streaks imaged repetitively during the mission showed no observable changes. Sagan et al. (1972) concluded that the 11ght streaks are comparatively stable and the datk streaks unstable. Both types of features apparently can be used as surface 
wind direction indicators and some attempts have been made to derive global wind patterns from streak orientations (Sagan et a1., 1973; Arvidson, in press).

Suspected aeolian features other than crater streaks Include laminated terrain (Murray et al., 1972), erostonal pedestal craters (McCauley, 1973), and irregular light and dark streaks withinin, on, and outside the rims of large craters. One Irregular dark zone within a crater $150 \mathrm{~km}$ in diameter in Hellespontus was imaged by the Mariner 9 narrow angle (telescopic) camera and was revealed to be an intercrater dune field about $60 \mathrm{~km} \times 30 \mathrm{~km}$ (Cutts and Smith, 1973). Thus, both erosional and depositional features of aeolian origin are observed on Mars.

Inttial analyses of aeolian features on Mariner 9 images pose several basic questions regarding the martian aeolian regime:

1) What are the criteria that may be used to separate aeolian depositional from aeolian erosional features?

2) What is the aerodynamic flow fleld over craters and what are the geological implications of the flow fteld in terms of zones of erosion and deposition? Does the flow field change significantly with changes in crater geometry?

3) What are the important parameters governing the movement of particles by wind on Mars and how do these parameters differ from those on Earth? For example, what wind veloctties on Mars are required for particle movement?

4) If the above three questions can be answered, is it possible to determine rates of erosion and depostition and particle size and/or composition of martian aeolian matertal from onalyses of spacecraft data and theoretical considerations?

As a means of developing answers to these questions, an Investigation is currently in progress that involves par:Lcle movement studtes using an atmospheric wind tunnel, qualitative wind tunnel simulations of aeolian erosion and deposition associated with craters, theoretical model studtes, and fleld 
studies of posstble terrestrial analogs. The investigation is a multidisciplinary effort of a geologiat, an aerodynamicist, and a planetary physicist. This report presents our preliminary results, which are presented in four sections. The first section tnvolves wind tunnel ctudies of individual particle movement. The second section is an application of wind tunnel results to Mars in order to estimate wind velocities and to determine the effect of Cortolis forces on surface stress under martian conditions. Section three concerns qualitative wind tunnel simulations of wind patterns over craters and section four comperes the wind tunnel results with fullscale features in the field.

\section{Acknowledgments}

Th1s paper was orginally presented in part at the Royal Soctety of London discussion meeting (May, 1973) on the results of spacecraft missions to Mars. We wish to thank Sir Harrie Massey, Sec. R.S. and the staff of the Soclety for their efforts in preparing the meeting. Special thanks go to Dr. J.E. Guest, Universit; of London Observatory, as the organizer of the meeting.

We wish to acknowledge Robert Haberle for his calculations of the geostrophic winds or . Iurs and David Wong for his assistance in some of the wind tunnel experiments.

Th1s work was supported by the office of Planetology Programs, National Aeronautics and Space Administration. 
WLND TUNNEL STUDIES OF AEOLIAN

PARTICLE MOVEMENT

Movement of particles by wind is a complex phenomenon. Bagnold's classic work (1941), based on wind tunnel studies and fleld observations, defines the bastc parameters and relationships of sand movement by wind. Drawing on his results and employing conventional techniques of wind tunnel scallng, we have verified Bagnold's (1941) fluld threshold experiments and extended the data over a wider range of particle sizes and densities, esperially as related to small grains for application to martian studies. We have not yet conducted impact threshold (saltating grains) and our results are restricted to discussion of fluid threshold experiments.

The important physical parame,ers describing aeolian processes are given In Taile I. These parameters can be arranged in the form of dimensionless simflitude parameters commonly used in wind tunnel simulations. A discussion of the simlititude parameters as applied to aeolian processes is presented in Append1x I. Although 1t is not possible physically to satisfy all parameters simultaneously In the wind tunnel, each Important paraneter can be studied Independently to determine its eifect on the aeolian reglme.

Because the surface pressure on Mars is significantly lower than on Earth, several facilities have been proposed in which martian dust storms could be simuiated under reduced pressure (B1dwell, 1965; Chang et a1., 1968). Using Bagnold's (1941) experimental data, Ryan (1964) and Axvidoon (1972) made theoretical calculations of grain movement under martian conditions. Adion et al. (1969) conatructed a low-pressure wind tunnel and conducted grain movement studies at presaures corresponding to those of Mars. Althcugh an exact experimental detexmination of cextaln parameters should be performed 
GLOSSARY OF SYMBOLS FOR AEOLIAN PARAMETERS

A

B

$\mathrm{C}_{\mathrm{L}}$

$c_{d}$

D

$\mathrm{D}_{\mathrm{c}}$

$\mathrm{D}_{\mathrm{p}}$

e

8

$\mathrm{h}$

$\ell$

L

et

$\mathbf{L}^{*}$

$\mathbf{R}$

$\mathbf{S}$

t

$\mathbf{T}$

V

$\mathbf{v}_{*}$

$v_{t_{t}}$
Bagno1d'a coefficient, $v_{*_{T}} / \sqrt{\frac{\rho_{P} g}{b} D_{P}}$

Particle friction Reynolils number at optimum diametex, $v_{*} D_{p} / y_{p l}^{\prime}$

Lift coefficient, $C_{L}=L / 1 / 2 \rho v^{2} s$

Drag coefficient, $C_{d}=D / 1 / 2 \rho v^{2} S$

Drag force, (force)

Crater diameter (length)

Particle diameter (length)

Coefficient of restitution

Acceleration of gravity (length/time ${ }^{2}$ )

R1pple height or reference height (length)

Length (length)

Reference length (length)

Wake length (length)

Monin-Obhokhev Stability length, $L^{*}=v^{3} C_{p} \rho T /$ KgH (1ength)

(where $C$ is spectific heat, $T$ is temperatux, $B$ is heat flux at surface) ${ }^{p}$

Reynolds number, VL/v

Reference area (length ${ }^{2}$ )

Time (t1me)

Turbulence factor

Velocity (1ength/time)

Friction velocity, (mgurface stressm $\sqrt{T / \rho}$ (length/time)

Threshold friction velocity

(1ength/time) 


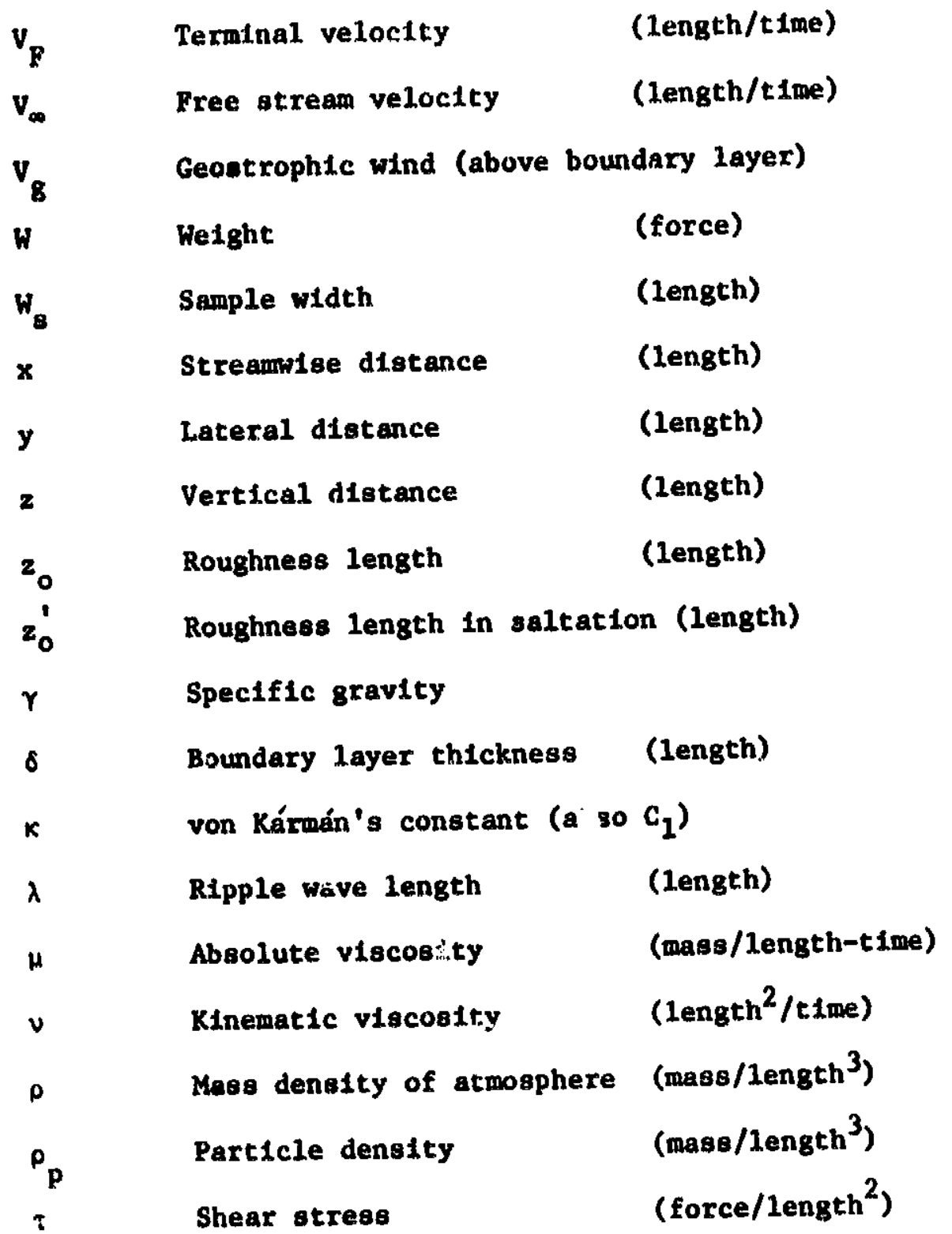


In a low-denstity wind tunnel, deposition and flow patterns over surface feacures (craters, etc.) can be modelled to some extent in a normal atinosphertc boundary-layer wind tunnel (Bddwe11, 1965), if cloge attention 18 pald to satisfying appropxlate modelling parameters and to the wind tunnel boundary layer configuration. Examination of these parameters (Appendix I) shows that most of the Important modelling parameters are more easily, and validly, satisfled in a normal atmosphertc wind tunnel.

A series of wind tunnel experiments was designed to gain additional knowledge of particle movement by wind, espectally as related to maxtian problems. Tests were conducted in an open-circuit ervironmental wind tunnel which has an adjustable celling in order to establish a zero pressure gradient. The test section $186 \mathrm{~m}$ long with a $1.5 \mathrm{~m}^{2}$ cross section; maximun speed $1 \mathrm{~s}$ about $40 \mathrm{~m} / \mathrm{sec}$.

\section{Threshoid Friation VeZocity Expeximents}

We wili first discuss experiments conducted on a flat surface, which determines the minimum or threshold stress needed to set sand particles into motion. Rather than dealing explicitiy with the threshold stress, $\tau_{T}$, we w111 instead use the threshold friction veloctty $v_{*}$, which by definition is related to $\tau_{T}$ by $\tau_{T}$ " $\rho V_{*}{ }_{T}^{2}$, where $\rho$ is the fluid density. Operationally, $v_{*} T$ can be determined more directly through a measurement of the vertical velocity structure.

Bagnold has suggestud that $v_{\star_{T}}$ can be expressed in terms of the other parameters of Interest as:

$$
v_{T}, A \sqrt{\frac{\rho_{P}-\rho}{\rho} B_{P}}
$$


where $\rho_{p} \quad 1 s$ particle density, $\&$ is acceleration due to gravity, $D_{p}$ is the mean particle diameter, and $A$ is a coefficient experimentally determined by Bagnold, who suggested that 1t was a function solely of the particle friction Reynolds numbex B. B 18 defined as

$$
\begin{aligned}
& B=v_{T} d / v \quad \text { (Bagnold, 1941) } \\
&
\end{aligned}
$$

where $\checkmark$ is the kinematic viscosity and $d$ is the mean surface roughness which is on the order of the particle diameter, $D_{p}$. If this expression for $v_{*} 1$ is correct, then in princlple, all one needs to do to determine $v_{*}$ for any environment is to measure $A(B)$. Hence, one bar wind tunnels are fust as valid as low pressure wind tunnels for applications to Mars with the approprlate correction for $v$ reflecting the lower martian atmospheric pressure. Bagnold's coefficient A is constant for particles down to about $50 \mu$ In diameter, then increases rapidly for smaller particles. This results, as Ba, nold (1941) discovered, in an optimum particle size for which threshold speed is a minimim, corresponding to a certain value of particle friction Reynolds number. Bagnold's coefficient $A$ for small particles was determined from limited experimental data, and only for quartz material.

Experiments to determine Bagnold's coefficient $A$ for a wide range of particle diameters and densities were conducted and the results axe shown in figures 3 and 4 . That the data shown in figure 3 for a wide range of particle sizes all fall close to en unique line Indicates the bastc validity of Equation (1) for the timeshold fäiction velocity and makes its appllcation to Mars meaningful. According to Bugnold (1941), the value of the optimum dlameter snould scale as the density ratio, $\left(p_{p} / 0\right)$, to the $(-1 / 3)$ power. The ininimum threshold speed ratio should he dicecty proportional to the one-third power 
of the density ratio. Limtied data in figures 3 and 4 comparing copper particles and glass spheres corroborate these trends.

Maklng use of Equations (1) and (2), we obtatn the following formulat relating the chreshold friction velocity $V_{t_{T}}$ and particle diameter $D_{p}$ to $A(B), B, \rho_{p} / \rho, B$, and $v$ (assuming that $\rho_{p} \gg \rho$ and $\therefore \frac{\rho_{p}-\rho}{\rho} \approx \frac{\rho_{p}}{\rho}$ ):

$$
\begin{aligned}
& V_{*_{T}}=A^{2 / 3}\left(\rho_{P} g \vee B / P\right)^{1 / 3} \\
& D_{P}=(B \quad v / A)^{2 / 3}\left(\rho / \rho_{p} g\right)^{1 / 3}
\end{aligned}
$$

Since A is simply a funition of $B$, we can generate a curve of $V_{*}$ 's a function of $D_{P}$ by piciling a set of values of $B$ and solving Equations (3) and (4). Thus, the desired curve can be generated without going 'hrough an iterative process, as would be required if Equacions (1) and (2) wert usex?. It should be noted that $v$ scales inversely as the fluid density $\rho$. The point on the curve in figure 3 where the relatively sharp breair. nccurs (A 0.146 and $P=0.58$ ) cocresponds to the minimum threshold friction speed. ior values typicai of an one-atmosphere wind tunnel, the values of mintmum $V_{*}$ and corresponding $D_{p}$ were calsulated for a range of values of particle density, using Equations (3) and (4) and the results are shcwn in figure 5. If a modelIng material is chosen to correspond to minimum threshold speed, it lis evident that if minlmun diameter is desired, the material should be of high denstity. However, materials of 1ightex diansity will result in somewhat lower mintmum threshold speeds.

Effret on Nonerodible Roughness and Lift on Threshold Speed

The roughness height, $\left(z_{0}\right)$, or simply the roughness of a surface, is a 
measure of the effective rellef of a surface. Th1s parameter plays a strong role in determintng the vertical wind profile close to the surface, which in turn determines the value of the friction velocity for a given wind speed above the boundary layer. Above we have determined the threshold friction speeds for flat surfaces overlain solely with the sand paxticles being studied. Here we consider the effect of the presence of numerous, 1arge, 1mmovable objects on the surface. In this circumstance, the roughness height $z_{0}$ is determined by the size of the large, nonerodible objects (to first approximation, $z_{0}$ is $1 / 30$ of the mean particle dlameter, or the height above the surface at which the wind velocity is zero). Chep1l and Woodruff (1963) observed that an increase in nonerodible rughness greatly increases the effective threshold speed. For a spherical particle resting on a bed of similar particles, a lift force acts through the center of the particle and a drag force (surface stress) acts at a distance $D_{p} / 6$ above the sphere center (Chepil, 1958). Equating opposing moments of 1ift, drag, and weight,

$$
v_{*_{T}}=0.373 \sqrt{\frac{\rho_{\mathrm{p}} \mathrm{g} \mathrm{D}_{\mathrm{p}}}{\rho}\left[\frac{1}{1+\frac{\mathrm{C}_{\mathrm{L}}}{9.6}\left(\frac{\mathrm{V}}{V_{*}}\right)^{2}}\right]}
$$

with a reference velocity for fully rough flow of $v=\frac{v_{*}}{0.4}$, n $\left(1+\frac{D_{p}}{z_{0}}\right)$, the effective $11 \mathrm{f}$ coefficient $C_{L}$ is solved for by letting $A=0.117$ (the: asymptotic value in $f\left(g\right.$ ure 3 ) and $D_{p} / z_{0}=30$; thus for fully rough flow, A may be written as:

$$
A=\frac{V_{*_{T}}}{\sqrt{\rho_{p} \& D_{p} / \rho}}-\frac{0.373}{\sqrt{1+0.776\left[\ln \left(1+D_{p} / Z_{p}\right]^{2}\right.}}
$$

It is assumed that the effective $11 \mathrm{ft}$ cofficient is unchanged for the other 
values of $D_{p} / 2$.. If large nonerodible roughness elements are present (i.e., high relief), then the equivalent roughness helght $z_{0}$ becomes greater than $D_{p} / 30$ and the coefficient $A$ increases according to Equa:ion (6).

To test the validity of Equation (6), values of threshold friction speed for several. matertals were determined for values of nonerodible equivalent roughness heights $z_{0}$ of $0.0104 \mathrm{~cm}$ and $0.338 \mathrm{~cm}$. The results of the experiments are shown in figure 6. Although there is quite a bit of data scatter, the results seem to substantiate the form of Equation (6). The letters NNR in figure 6 signify that no nonerodible roughness elements were present in those tests and that the ratio $D_{p} / z_{o}$ is 30 (or slightly higher in the transition range). Figure 7 shows the threshold friction speed as a function of particle diameter for one of the test materias (heavy glass spheres). The bottom curve is derived from the curve of figure 3 and the other curves from Equation (6) and again the trend seenis to be substantiated by the experimental results.

Although some investigators have ignored the effect of particle lift in attempting to predict threshold friction speed, the effect of lift is apparently important. Bagnold $(1956,1973)$ has stated that the initial upward acceleration of a particle (not struck by another particle) from the bed is due to a 11ft-force but that the 1ift force becomes very small shortly afte- the particle has lifted off the bed. The lift force is due to the very high mean velocity gradient very near the surface.

An effective lift coefficient at threshold was calculated from the data of figures 1 and 2. Although the results are rather tentative, initial calculations indicate the lift is an important parameter for particle threshold novement, particularly for low partirle friction Reynolds numbers. However, additional work is required before a definltive statement can be made. 


\section{PREDICTED AEOLIAN CONDITIONS \\ FOR MARS}

\section{Threshold Velocities}

We now make use of our wind cunnel results to predict the threshold friction velocities for Mars. To do this, we make use of Equations (3) and (4) and the curves previously discussed that give the dependence of the Bagnold's coefficient $A$ on the particle friction Reynolds number $B$. In addition we must specify the values of $g, \rho_{p}, \rho$, and $\nu$ appropriate for the conditions on Mars. The acceleration of gravity for Mars is approximately $375 \mathrm{~cm} / \mathrm{sec}^{2}$. We carry out our nominal calculations for a particle density of $2.7 \mathrm{gm} / \mathrm{cc}$, a value typical of terrestrial sands. The value of $p$ is obtained from the perfect gas equation for a spectfied value of surface pressure and an assumed atr temperature of $2400 \mathrm{~K}$. Finally since the martian atmosphere is composed principally of carbon dioxide, we obtain the value of $\nu$ by dividing the dynamic viscosity of carbon dioxide, $n$, at $240^{\circ} \mathrm{K}(1.21 \times$ $10^{-4} \mathrm{gm} / \mathrm{cm} / \mathrm{sec}$ ) by $\rho$. We note that for the conditions of intarest $n$ does not depend on $p$.

F1gure 8 shows the dependence of threshold friction velocity upon particle diameter for a surface pressure of $5 \mathrm{mb}$, which is representative of the mean surface pressure for Mars. Also given ts a simllarly generated curve, which makes use of the values of A found by Bagnold (1941). We see that in a crude sense the two curves agree with one another. However, Bagnold's data imply friction velocities lower by about $20 \%$ than those implied by our wind tunnel data. In addition, the value of the particle diameter having the smallest threshold velocity is about twice as large for Bagnold's data as for ours. As dtscussed above, our data are much more complete near the 
minimum in the threshola curve than were those of Bagnold. Our wind tunnel results show that the optimum (lowest wind velocity) dlameter is about 300 microns at a surface pressure of $5 \mathrm{mb}$ (compared with $200 \mu$ for $25 \mathrm{mb}$ of Ryan, 1964).

Because substantial elevation differences are present on Mars, we have calculated the threshold friction velocity for several values of the surface pressure. Figure 9 shows the results of these calculations for values of the surface pressure of $2 \frac{1}{2}, 5$, and $10 \mathrm{mb}$. As can be seen, the threshold velocities are substantially lower for the high surface pressure case than for the low surface pressure case. In addition, the value of the particle diameler at the minimum in the threshold curve shifts to a somewhat smaller diameter as the pressure increases (In agreement with Ryan, 1964).

The above calculations were carried out for a particle spe:lfic gravity of 2.7 , a value typical of terrestrial sands. However, it is concelvable that this value may vary somewhat, depending on the composition and prior history of the grains under study. For example, the specific gravity might be as high as 4 if the sand is particularly rich in iron, or it may be as low as 1 if the particles contaln very fine pores, as might occur for volcantc ash. The latter seems somewhat unlikely based on terrestrial experfences, which indicate that porosity effects are important only for larger sized particles, because the pores generally are not as small as several microns. Figure 10 11lustrates the dependence of particle size and threshold velocity on particle density for the minimum in the threshold curve. These results were obtalned for our nominal case of $5 \mathrm{mb}$ surface pressure. As the particle density increases, the threshold velocity increases and the particle size decreases. Thus, mottion on Mars will occur most read1ly for sands having a 
low density and will involve particles whose size 1s about 400 microns. For all the cases of surface pressure and particle density that seem likely for Mars, the particle size is on the order of several hundred microns at the minimum on the threshold curve. As we will see in the next sections, even for the mintmum threshold friction velocity, che required wind speed to initiate motion is quite large. Thus, if particle motion is to occur with any sort of frequency on Mars, as seems to be the case, there should be a substantial population of grains whose size is several hundred microns. This inference about the size of the martian sand grains is in good agreement with values for most axeas sampled by the Mariner 9 infrared radiometer (Kieffer, et al., 1973). This argument can be put In a somewhat different way. Sagan and Pollack (1969) have argued that those grains that are easily set in motion will eventually cover grains that are not unlike planet-wide conditions on Earth where oceans serve as settilng traps for dust. As a result, there will be a substantial population of surface grains whose size is close to the size at the minimum in the threshold curve. Th1s hypothesis seems to be valdd for terrestrial sand deserts contained in closed basins. Sagan and Pollack have also pointed out that such sized particles will not: go into suspension on Mars, and thus a second population of grains, of much smallex size, must be present on Mars to arcint fo: the particles put into suspenston during the great dust storms. These particles ara set into motion not directly by the winds, but indfrectly by the impact of a saltating particles from the large stze population.

Est imate of the liootrophic Wind Velocity at Fluid Threshold and the Angle of Rotation Through the Boundaxy Layer

Csanady (1.972) derived a set of expressions relating the wind $v_{g}$ above the boundaxy layer to the friction veloctty $v_{\star}$ and also dextved an expression 
for the rotation angle $a$ between the wind above the boundary layer and the direction of the stress at the ground. The expressions are valid at midlatitudes where the Cortolis force is important. Toward the Equator, $a$ will tend toward zero, while the ratio of $v_{8} / v_{*}$ may change somewhat. According to Csanady:

$$
\begin{aligned}
& v_{g} / v_{*}=\frac{1}{\sqrt{c_{d}}} \\
& \alpha=\sin ^{-1}\left(11 \sqrt{c_{d}}\right)
\end{aligned}
$$

where $c_{d}$ is the drag coefficient. $C_{d}$ in turn may be expressed as a function of two dimensionless parameters which take account of the roughness of the surface, the gravity, the Coriolis parameter, and the temperature difference between the ground and the alr above it. In the case of Mars, there are large temperature difserences between the ground and air above it near noon and at night. However, for the case of no nonerodible roughness elements, the roughness height is so small that the value of $C_{d}$ is not greatly affected by the large variations from neutral stability. Using the graphs and equations of Coanady (1972), we estimate that $c_{d} \sim 5 \times 10^{-4}$ neax the minimum in the threshold velocity curve at a pressure of $5 \mathrm{mb}$. Inserting this value in Equations (7) and (8), we find that at a surface pressure of $5 \mathrm{mb}$, the wind velocity must exceed approximately $110 \mathrm{~m} / \mathrm{sec}(400 \mathrm{~km} / \mathrm{hr}$, or 0.4 times the speed of sound on Mars!) for gxatn motion to occur on a smooth, flat surface. Such a wind is comparable to the highest winds expected on Mars; thus, a general dust storm w111 not occur too frequently on Mars. Instead, more frequent grain motion events will occur near craters where the local. friction velocity corresponding to a given calculated geostrophic wind can be as much 
as 2 or 3 times as large as that for a flat terrain.

The angle $\alpha$ found from the above calculation $1815^{\circ}$. At midlatitudes, above the boundary layex the corlolis force is balanced by the pressure gradient force, while within the boundary layex, both the Corlolis force and frictional forces balanced the pressure gradient force. Thus, above the boundary layer, the wind is approximately parallel to 1sobars, while within the boundary layer, the wind direction gradually changes direction so it has a component directed towards lower pressure. As a result there wi:1 be a slight angle $\alpha$ between the direction of surface stress and geostrophic wind (see Halton, 1972). The geostrophic wind is to the right of the surface streak in the northern hemisphere and to the left in the southern hemisphere. This factor needs to be taken into account in analyzing streak directions. Angle $\alpha$ decreases in latitudes toward the Equator. The above estimate of $\alpha$ should at present be considered only as an approximate value since it is very difficult to model all the factors that influence $\alpha$ in the boundary layer. The above estimate of $v_{8}$ is better established. 
MODELLING OF AEOLIAN PROCESSES

ASSOCIATED WTTH CRATERS

A series of experiments is in progress in order to simulate aeolian processes associated with craters. In contrast to the experiments described In the first section, these experiments are qualitative and were made without regard to problems of scaling to full-size structures under martian conditions. The experiments are progressing along three lines: 1) aeolian deformation of craters modelled in loose sand, 2) loose sand blown over solld crater (non-deformable) models, and 3) studies to determine the influence of crater geometry on the size, shape, and position of zones of erosion and deposition assoctated with craters.

Each experiment is described as a run. Sequential still photographs and time-lapse motion pictures were made during each run. All still photographs are oriented with the 1llumination from the upper left-hand corner and the wind direction from the left toward the right. Unless otherwise indicated, wind velocities were obtained with a hot-wire anemometer in the free stream above the mode1. Quartz sand, $120 \mu$ in diameter was used in most of the experiments.

\section{Craters Suiject to Aeolian Deformation}

This series of experiments involves craters of two geometries, raisedrim craters and nonratsed-rim craters, molded in 1oose $120 \mu$ sand and subjected to steady winds. The objective was to determine the zones of preferential erosion and deposition around the crater and to determine the progressive geometric distortion of the crater. For some of the runs in this sertes, longttudinal (parallel to whd direction) and transverse proftles were obtatned to determine the changes in surface relief. 
Bun 21. F1gure 11 shows sequential photographs for Run 21 in which a nonralsed-rim crater (bowl-shaped depression in the sand) was subjected to wind of $307 \mathrm{~cm} / \mathrm{sec}$ veloc1ty. The crater outline in plan view became progressively ovold, with the axis parallel to the wind direction. Sand ripples were only slightly deflected as they passed the lateral edges of the crater. There is a zone in the les of the crater in which no ripples formed and the surface remained undisturbed. This area is probably analogous to the "shadow zone" of full-scale sand dunes, in which relatively little erosion occurs.

Run 12. Figure 12 shows sequential photographs for Run 12 in which a raisedrim crater (In contrast to Run 21) was subjected to relatively low velocity (250 cm/sec) wind. In a manner simflar to Run 21, sand ripples passed around the crater rim and merged at a point about $3 / 4$ of the crater diameter in the lee of the crater, forming a triangular-shaped shadow zone. In plan view, the crater assumes an ovold outline pointing upwind. Figure 13 shows sequential longitudinal profiles in which the windward and leeward crater rims became asymetric during the run, as would be expected. Although the entire crater migrated downwind, the upwind rim moved more rapldiy (causing the ovold outline to progressively flatten, figure 12), while the deepest part of the crater (the original crater center) remained fixed in place. From this and subsequent runs, it was concluded Initlally (Greeley, 1972) that a raised-rim crater formed entirely in loose sand could be treated as a combination parabolic dune (windward $r \mathrm{~lm}$ ) and Larchan dune (1eeward $\mathrm{r} 1 \mathrm{~m}$ ) in regard to erosional and deposttional patterns This concluston, however, was an oversimpliflcaticn that does not account for other, more complex aeolian patterns that develup in association with craters. Bun 8. Figure 14 sisows the sequentlal development of Run 8 in which all conditions were identical to Run 12 except the wind velocity which was neariy 
double (approximately $450 \mathrm{~cm} / \mathrm{sec}$ ). The last plcture in the sequence represents nearly stable condttions, 1.e., no significant changes occurred after this time-frame. As In Run 12, the crater becane ovold and developed a leeward shadow zone. At this higher velocity, however, depressions developed in the lee of the lateral crater rims. The depressions are erosional and evidently represent zones of relatively high wind velocity. They apparently result from vorticies shed from the crater $\mathrm{rim}$, as w1ll be discussed beliow. Figure 15 is a comparison of Run 8 results to a small crater imaged by Mariner 9 in Mare Tyrrhenuin. The surface wind airection arrow shown for the Mars picture was derived from crater tall streaks over a wide geographic range in this area. The dark zones correspond to the erosional depressions of Run 8 , both in theil position and relative stize as compared to the crater diameter. By analogy, we Infer that the lateral dark zones on the martian cracer are the result of aeolian erosion. Simllar dark zones occur on small craters in other regions of Mars.

Figure 15 also shows a similarity in crater outline of Run 8 and the martian crater. Both features are ovoid, pointing directly upwind and it 1 s tempting to infer that the martian crater deformation resulted from aeolian processes.

Data from additional runs involving raised-rim craters molded in loose sand showed that, as the velocity is increased, the lateral erostonal depressions lengthen. At highest velocities $(700-800 \mathrm{~cm} / \mathrm{sec})$ it was not posstble to determine definitive patterns because sand ripples formed very quickly and overrode the crater and lateral exostonal depressions. For higher velocities, solid crater models and loose sands were used. 


\section{Solid-Model Cratex Experiments}

Th1s series of runs involves craters modelled as solid forms that were not subject to deformation, in contrast to the serles described in the previous section. Three general types of experiments were conducted with solid models: 1) loose sand introduced into the free stream upwind of the model and allowed to saltate across the model and collect in zones of deposition, 2) models in which the crater was filled to the rim with loose sand (other areas free of sand) and subfected to wind erosion, 3) crater and surrounding floor covered by loose sand and subfected to wind. In all three cases craters with raised-rim geometries were used.

Fun 29. Figure 16 shows the sequential filling of a solid-model ratsed-rin crater with sand which was introduced into the free stream upwind of the model. Sand initially collected in the down-wind part of the crater floor (figure 16, "A"), then migrated (arrow) across the floor toward the left (In the opposite direction from the free stream flow direction) and collected in the lee of the windward crater rim (f1gure 18, "B"). This reverse flow on the srater floor was observed in all experiments of this configuration. Simultaneously with the sand deposition within the crater, sand collected on the upwind side of the windward crater rim (figure 16, " $c$ "). Eventually, sand was eroded from the zone of deposition at " $B$ " and las carried over both lateral rims (f1gure 16, "D"); other sand grains were carried over the leeward rim and deposited in the tmmediate see of the crater rim (f1gure 16, "E"). Free stream veloctity for Run 29 was $435 \mathrm{~cm} / \mathrm{sec}$. The run was terminated after relatively stable conditions ensued.

stmilar runs at higher free stream velocities produced essentially the same patterns of depostition, except that the amount of sand collected in each zone was less than that at the lower speed. 
Fun 32. Figure 17 shows the sequential development of a solid-model crater (ame model as used In Run 29, fIgure 18) In which the crater was f11led to the riw with 120 sand (other surfaces free of sand). As the run progressed, Band was Initlally eroded from the downwind part of the crater Interlor and redeposited in essentlally that same pattern that developed for Run 29 . T's: run continued until stable conditions ensued; free stream velocity was 285 $\mathrm{cm} / \mathrm{sec}$. At higher speeds, the same pattern developed except that less material remalned in the crater.

Run $I-F-14$. Figure 18 shows the sequential erosion of a solfd-model crater and surrounding surface that were buried to a depth of 1 can with $200_{\mu}$ glass particles. The bilobate pattern of erustonal depressions is similar to the pattern of Run 8 (figure 14). Subsequent experiments under a variet; of conditions confixmed the common development of bilobate erosional depressions off the lateral rims of raised-rim craters. We believe that the wind pattern over the Is similar to wind patterns observed over small protuberances (with small height-to-diameter ratios) in boundary layers, as descr1bed by Gregory and Walker (1951) and Sedney (1972) for laboratory scale tests. If so, there would be a horseshoe vortex wrapped around the leading edge of the crater rim with the tralling vortices emanating downstream from the crater sides. The axes of the vortices are parallel to the wind direction. The bilobate erosional depressions can be accounted for by the scouring action of the vortices. The tangential component of velocity in each tralling vortex is outward away from the crater wake centerline near the surface, and inward above the vortex cores. The axial velocity components near the surface fust downstream froin the crater rim would be minimum on the wake centerline with maximum velocities on either side of the wake of greater magnttude than outside the wake zone. 
Preliminary results Indicate tihat as the velocity increases, the s1ze, shape, and position of the bllobate exostonal zones change, Generally, higher free-stream velocities cause the erostonal zones to lengthen, widen, and shift theix position toward the crater wake centerline until they eventually merge and form one large erosional zone in the lee of the crater (figure 19). Th18 may be accounted for by the fact that, far downstream, the two axial velocity maxima merge, thus developing a muximum wind speed on the crater wake centerline. A triangular-shaped deposition zone remains in the Immediate lee of the crater. It must be emphasized, however, that parameters other than wind velocity can change the shape and position of the tralling vortices. These parameters include time, crater height-diameter ratio, and others; their effects are currently being studied.

Runs 217, 218, and 219. Figure 20 shows the sequent1al erosion for Run 217 of a ralsed-rim solid model. (crater and base) that was covered with a thin layer of $120 \mu$ sand glued to its surface (in order to provide a roughness equivalent to the diameter of the loose sand); the entire model was then covered with loose sand and subjected to wind. Free stream velocity was $572 \mathrm{~cm} / \mathrm{sec}$. Bilobate erostonal zones developed in a pattern simtlar to Run 8 and I-F-14 (figures 14 and 18). The run was continued until stable conditions were obtained, at which point nearly the entire model floor was swept free of loose sand by wind. Sand remalned in the floor zone of the crater and in.a plke-shaped zone in the lee of the crater.

Figure 21 shows the sequential photographs for Run 218 , which was identical to Run 217, except that the free stream velocity was inttally $330 \mathrm{~cm} / \mathrm{sec}$ and gradually increased (only after stable condictons ensued for each Incremental increase) to a final veloctty of $695 \mathrm{~cm} / \mathrm{sac}$. Agatn, the bllobate erostonal zones developed. At the higher velocity $(695 \mathrm{~cm} / \mathrm{sec})$ the 
pike-shaped sand zone in the lee of the crater was reduced in s1ze and the h.1 lobate erostonal zones became more pronomced. Run 21.9 was a continuation of Run 218 except that the free stream veloctty was 1ncreased to $838 \mathrm{~cm} / \mathrm{sec}$. Under the higher veloctty the sand zone in the loe of the crater formed a distinctive trilobate pattern. Sand also rematned on the upwind side of the windward crater rim and in the crater floor zone. Erostion occurred in the downwlind part of the crater floor as noted in previous runs.

Figure 22 compares the results of Run 219 with a small (about $2 \mathrm{~km}$ in dlaneter) martian raised-rim crater in the region northwest of Memnonia. The surface wind arrow was derived from crater streaks in the region. The trilobate 11ght-colored pattern of the martian crater bears a striking resemblance in regard to its shape ard relation to the crater and wind direction to the sand deposits of Run 21.9, suggesting that the 11ght material in the wake of the martian crater is the result of deposition, rather than erosion. The suggestion is further enhanced by the presence of a white zone on the upwind side of the windward rim of the martian crater, and the dark zone in the wake of the crater beyond the trilobate light pattern. The dark zone would correspond to the zone of erosion resulting from the merging of the axial velocity maxima along the wake centevitine, as described above. While the interpretation that the white zones of the martian crater are depositional, we do not imply that all white streaks assoctated with martian craters are depositional. The pattern 1llustrated in figure 22 is rare in the Mariner 9 images ( $1 t$ is on a " $B$ " frame, and, hence, represents a very ama11 sample surface). 


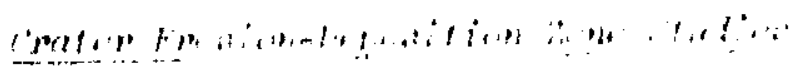

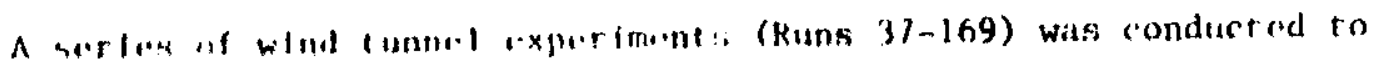

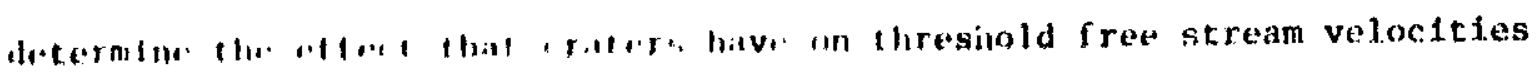

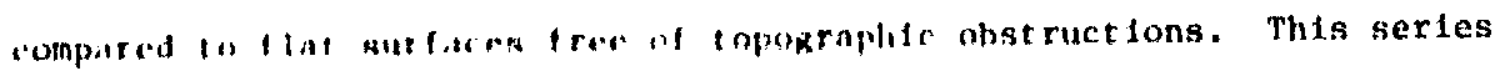

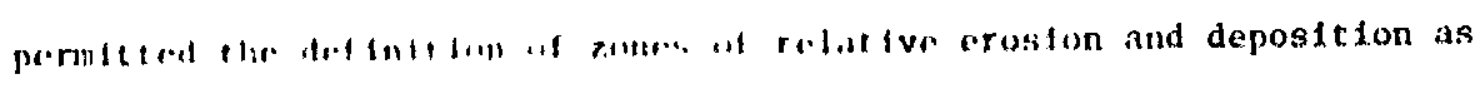

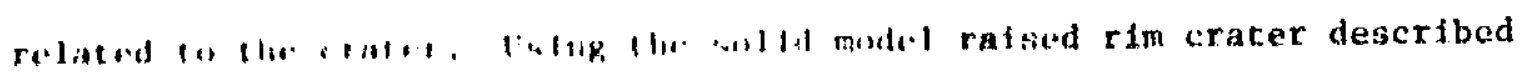

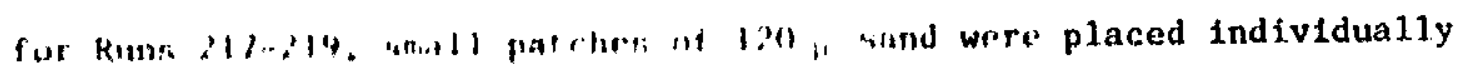

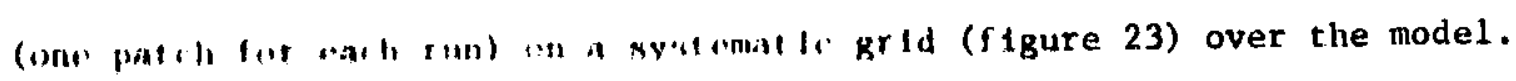
For cach run, lli, wind apend wa, : lobily increased in graduated steps until the flrst sand gratus hegall to muve consistently (threshold), as observed through a toleseopl. The wind speed at this point is the threshold free stream velocley for the sand as related to a particular location in, on, or near the crater. low threshold froe stream velocities represent relative erosion (gralns caslly moved); high threshold free stream velocities represent relative depostition. In addition, observations were made for specific grain movement directions in order to determine surface stress direction over the model. The results of this series are discussed by zones identified on figures 23 and 24 .

Zone 1. Points on the grid (fjgure 23) close to the crater had higher threshold free stream veloctities than those farther upwind. The crater rim is a bluff body (a broad surface facing the wind) which restets the passage of atr. Upwind of the crater the external atrstream begins to "feel" the obstruction and a posttive pressure gradfent forms in front of the crater. Some of the fluid partiles (atr) wt1l he slowed down, some will be stopped, and others will be reversod. Reverse flow by sand gratns was observed at the front rim of the crater. A point of attachment was close to the bottom of the windward crater $r$ in (figure 24). Above the point grains were carried up and 
over the rim; at the level of the potnt, the grains moved sldeward; and below the point grains were moved downward in reverse flow. The sideward motion resulted from the horseshoe vortex around the crater $\mathrm{xim}$. Zone 2. Regions on the flanks of the crater had relatively lower threshold free stream velocities, evidently due to vortices. A horseshoe wortex wraps around the side of the crater, similar to that described by Gregory and Wa1kex (1951) for p111 box structures.

Zone 3. The downwind side of the leeward $\mathrm{rim}$ is a zone of relative deposition. Sand was carried over the leeward crater rim from regions of lower threshold free stream velocity. Particles deposited here were subsequently eroded more slowly (after the sand scurce was diminished). Zone 4. Downwind from the crater the threshold free stream velocity is low and relatively constant, signifying a region of vortex action. The a1r stream which flows over the leeward rim and curls down meets the horseshoe vortex, resulting in a reglon of high erosion. The alr on either side of this region is apparently unaffected by the crater and free stream velocities required to move particles were on the order of $20-25 \%$ greater than those Inside the wake zone.

Zone 5. Aix flow within the crater appears to be very complex. Loose sand on the upwind part of the leeward rim was carried by reverse flow across the crater floor, opposite to the main wind flow and deposited in the lee of the windward rim. Within the crater, the leeward $r$ im is a region of erostion while the windward $\mathrm{rim}$ is a region of deposition. 
TERRESTRIAL FIELD STUDIFS OF AEOL.IAN ACTIVITY ASSOCIATED WL'TH CIRCULAR BASINS

As a means of valtdating the preltminary laboratcry dritrminat lins of the flow fleld over craters, aeollan processes assoclated wlth litger circular basins on Earth are currently helng studied. These Include: 1) raised-rin crater $6 \mathrm{~m}$ in diameter dug in a plowed (1eld, 2) ruvirw of Wolf Creek Crater, Australla, a meteorite Impact crater $1.2 \mathrm{~km} \mathrm{in}$ diameter, and 3) Eagle Cove, Idaho, a semictrcular ban in $5.6 \mathrm{~km}$ in diameter which contains an extensive and dune fleld. In each case, the primary interest is in determining the aerodynamic flow fleld over tha: structure and in determining zones of aeolian eroston and deposition.

\section{Artificial Baised-Rim Crater}

A raised-rim crater $6 \mathrm{~m}$ in diameter was dug in loose soll on a $\mathrm{flat}$ field of the Iowa State iniversity campus prior to the Winter, 1972. The objective was to determine relative zones of erosion and deposition. shown by drifted snow pattexns following mafor snow storms of known wind velocity and direction. Trlangular-shaped deposits of snow accumulated in the Immediate wake of the crater and bilobate patterns of erosional zoncs formed in the same configuration observed in the wind cunnel slmulations. The modeling parameters in this particular field test were estimated to be $\mathrm{V}(\mathrm{h})^{2} \mathrm{gD}_{\mathrm{c}}=0.4$ (based on same relative $\mathrm{h} / \mathrm{L}$ as the $\mathrm{w}$ lnd tunnel, $\mathrm{V}_{\mathrm{F}} / \mathrm{V}_{*}=5.0 \pm 3$, and $\%(h) / V_{p}=4.0 \pm 1, V(h)=450 \mathrm{~cm} / \mathrm{sec}$. Similar results were observed after seviral wher snow storms.

\section{Wolf Creg Metronite Crater, Australia}

Wolf Creek Crater is an Impact structure about $1.2 \mathrm{~km}$ in dlameter, formed In bedded quartzite (McCa11, 1965). It has a distinct raised rim (f1gure 25) 
and is surrounded by relatively flat sand platns. Its geometry, the extatence of aeolian matertals, and wind from a prevalling direction make 1t an 1deal structure for determining flow flelds over large-scale craters. Figure 26, adapted from McCal1 (1965, figure 3a,b), shows the approximate ovold crater outline orfented to the prevaling wind direction and the zones of erosion and deposition. Sand deposits are on the upwind side of the windward $\mathrm{rim}$, on the floor of the crater, in a horseshoe pattern wrapped around the crater rim and trajling downwind, and in a zone in the immediate lee of the crater rim. Zones of erosion are indicated by McCall (1965, figure $3 a, b)$ as areas in which the aeolian material has been swept free, exposing the underlying bedded quartzite. These axeas form a bllobate pattern between the zones of sand accumulation. The overall resulting pattern is essentially the same as derived in wind tunnel simulations.

\section{Eagle cove, Idaho}

Eagle Cove, Idaho, is an old meander loop of the Snake River (figure 27) above $5.6 \mathrm{~km}$ in diameter, previously described (Greeley et al., 1971, Murphy and Greeley, 1972). The subctrcular basin contains a large central sand dune and several sma11, complex dune fields. Eagle Cove is a settiling basin for wind-borne particles carried by the prevaling northwest winds. A secondary wind direction $18180^{\circ}$ to the prevaliting wind and is evidently responstble for malntalning the large dune in the center of the basin, rather than against one wall of the crater as might be expected if only one dominant wind direction were involved (Murphy and Greeley, 1972).

The size and distribution of aeolian depostes in relation to Eagle Cove and the prevaliting wind directions have implications for the interpretation of martian aeolian features associated with craters and eroded ctrcular 
basins. The central sand dune is nearly the same helght as the basin rim and contains a small crater-1ike blowout; as such, it could be identified on low-resolution spacecraft 1magery as the central peak of an Impact crater, or a constructional feature of a volcantc crater. Thus Eagle Cove offers an alternative explanation for posttive features in craters subjected to aeolian processes and bimodal wind directions.

In addition to the large central dune and inter-basin dune flelds, Eagle Cove has a large sand dune fleld draped over the windward rim onto the basin floor. Many of the martian craters have similar distributions of dark zones on the crater rims and it has been demonstrated (Cutts and Smith, 1973) that some of the crater-assoclated dark zones are dune fields. In the case of Eagle Cove, the dune field is on the upwind stde of the crater. 
SUMMARY AND CONCLUSIONS

Studies of aeolian processies are currently in progress along three general lines: parametric wind tunnel studies of grain movement, wind tunnel simulations of the aeolian modification of craters, and field studies of posstble terrestrial analogs. From these studies we are attempting to determine the general flow fleld over craters in order to define aeolian deposition and erosion patterns and to derive the influencing parameters for the application of the results to the martian aeolian regime. Initial results from these studies are applied tentatively to the interpretation of selected martian surface features.

Threshold speed (restricted to fluid threshold) experiments have been conducted in an atmospheric wind tunnel in order to:

1) Verify Bagnold's (1941) expressions for the aeolian movement of particles by extending the emplrically derived data uver a wider range of particle specific gravities $(1.3$ to 11.35$)$ and particle diamecers $(8 \mu$ to $1290 \mu)$.

2) Better define particle movement by ind in the range of particles with low particle friction Reynolds inmbers, Important for martian applications.

3) Study the effects of nonerodible roughness and 11ft on particle motion.

Using the results from these experiments in combination with the appropriate parameters for Mars, predictions are made for martlan aeolian conditions. Threshold velocities as a function of particle. size were calculated for three atmospheric surface pressures on Mars, $2.5 \mathrm{mb}, 5.0 \mathrm{mb}$ and $10.0 \mathrm{mb}$. As the pressure decreases (corresponding to higher topographlc elevations), the optimum particle size (corresponding to minimum wind veloctty) increases. For a nominal pressure of $5 \mathrm{mb}$, optimum particle size is about $300 \mu$; the 
corresponding geostroph1c wind to set the grains in motion of flat surfaces without topographic obstructions is extremely high, on the order of 400 $\mathrm{km} / \mathrm{hr}$. However, near craters the local friction veloctity can be increased 2 or 3 times over that of a flat terrain. It is interesting to note thrt the proposed Viking 75 landing sites are on smooth, flat plains where the friction velocity will be lower and hence subfect to less aeolian activity. Coriolis effect on streak orientations must be taken into account in attempting to determine global wind patterns from surface features. In midlatitudes on Mars, the deflection of the wind is about $15^{\circ}$ to the right of streak orientations in the northern hemisphere and $15^{\circ}$ to the left in the southern hemisphere.

Several qualitative wind tunnel simulations have been conducted over crater models. A general flow field has been dertved tentatively for one raised-rim crater geometry and the associated zones of relative aeolian erosion and deposition determined. As the turbulent boundary layer approaches the crater $\mathrm{x} \mathrm{im}$, it begins to "feel" the obstruction and a pressure gradient develops which causes reverse flow of wind-transported material in front of the crater. In addition, a horseshoe vortex wraps around the crater rim, forming two trailing vortices of the lateral flanks of the crater with the vortex cores parallel to the surface. Two axial velocity maxima occur to the lee of the crater on elther side of the wake centerline. Under certain conditions (e.8., high wind velocities), the two velocity maxima merge on the crater wake center line to form a zone of high surface stress. Flow over the crater is extremely complex and is only partly defined at this the; however, reverse flow occurs across the crater floor. 
The flow fleld described above results in a pattern of aeolian erostion and deposition which appears to be charactertstic for raised-rim craters. Deposition zones are as follows: 1) upwind side of the windward crater $\mathrm{rim}$, 2) in the lee of the windward crater $\mathrm{rim}$, resulting from material carried over the rim directly, and from inaterial deposited by the reverse flow across the crater floor, and 3 ) in a trilobate pattern in the lee of the crater. Erosion zones Include the upper areas of all windward-facting parts of the crater rim, the downwind part of the crater flcor, a zone off both lateral flanks of the crater rim (corresponding to the position of the horseshoe vortex), and, in some cases, a zone along the centerline of the wake downwind from the crater.

Although we have not as yet determined all the important scaling parameters for simulating aeolian processes on Mars, it would appear that the problem of scaling from wind tunnel models to full size craters on Earth may not be so great, as evidenced by the existence of essentially the same patterns of relative exosion and deposition in wind tunnel simulations as was observed for the $6 \mathrm{~m}$, artificlally constructed crater and the $1.2 \mathrm{~km}$ impact crater (both raised-rim structures).

The shape and position of the defined zones and their relation to the crater geometry and prevalling wind direction have been applied to the interpretation of suspected aeolian features assoctated with martian craters. In some cases, dark zones appear to be the result of erosion and 11ght zones the result of deposition. In other cases (e.g., the intercrater dune fleld of Cutts and Smith, 1973) dark areas result from deposition. In addition, although the examples are not discussed here, some of our wind tunnel simulations would indicate that some light zones could $x$ asult from erosion. Thus, 
both 11 ght and dark zoncs can result from elther relative erosion or relative deposition. While it may be posstble to Identify the process on the basis of morphology in some cases (e.8., figure 22), other parameteas should also be cons1dered. The relative Zuminance, or the degree of 11 ghtness or darkness of a surface, depends upon several factors that are influenced by aeollan activity. These include grain size, grain composition, and ripple wave length. Zones of high wind speed, or relative erosion, could result in large grains, long ripples, or concentrations of high-density material. Although some work has been done to study the effect of grain size on relative luminance, the three main velocity-dependent parameters (grain size, ripple length, composition) have not been taken into account in combination. It is apparent that unt1l the relative effects of grain size, ripple length, and mineral composition taken in combination are determined, it will not be possible to fully understand aeolian processes on Mars.

Although not all modelling parameters can be satisfied in the wind tunnel, a great deal of information can be gained about the nature of the flow fleld and the resulting deposttional and erosional features. A systematic series of experiments 1s currently underway, in wh1ch each of the major modelling parameters is varied independently, to determine its effect upon eollan features. This is being done by varying crater dlameter, tunnel speed, and modelling material. The results watl not only enable us to determine effects of each simflitude parameter, but will also assist greatly in later numertcal experiments in whtch all modelling parameters can be satisfled. 
APPENDTX I

MODELLING AEOLIAN THENOMENA

Several wind tunnel Installations have been constructed to Investigate the effects of wind on sand and soll movement. The primary factlity for studying the transport of sand by wind was that of Bagnold (1941). Expertments sonducted in his wind tunnel resulted in curves and equations for threshold friction speed and mass transport of sand due to wind. Another factlity used mostly for studying wind erosion of soil is described by Chepil and Woodruff (1963). Other wind tunnels for the study of soll and sand transport by wind have been built (Ford, 1957; Malina, 1941).

The structure of the turbulent planetary boundary layer on Earth has been studied extenstvely (e.g., Lumley and Panofsky, 1964; Plate, 1971). Jensen (1958) and others have observed that the lower portion of the plenetary boundary layer (In a neutrally stratified atmosphere) follows the logarithmic law

$$
\frac{V(z)}{V_{\star}}=\frac{1}{K} \ln \frac{2}{z_{0}}
$$

where $V_{*}$ is the fristion velocity and $k$ is von Kármán's constant (Ko0.4). Jensen showed that for simulation of the atmospheris boundary layer, the roughness parameter for the wind tunnel floor must. scale with the roughness paraneter in nature, t.e.,

$$
\frac{{ }_{0} M}{z_{0}}=\frac{1}{L}
$$

Most investigators have relled on the long test section to sipulate the turbulent boundary layer profile so the mode1 is immersed 1 n the boundary 
layer (Davenport and Syumov, 1968; Cermak, 1971). However, 1t is possible, although perhaps not as destrable, to produce thick boundary loyers with the proper scaled velocticy proftles in shorter test sections (Owen and 21enktew1ce, 1957, Counthan, 1969, Sundaram, et al., 1972). Effects due to a nonneutral atmosphere (stable or unstable) can be simulated to some extent by cooling or heating the tunnel floor (Cermak, 1971).

In order to overcome some of the problems in scaling from wind tunnel models to full-scale features, important parameters describing aeolian processes can be arranged in the form of dimensionless similitude parameters.
2. $\frac{D_{P}}{L}$
length
2. $\mathrm{V}(\mathrm{h}) / \mathrm{v}_{\mathrm{F}}$
reference to particle terminal speed ratio
3. $[v(h)]^{2} / g \mathrm{~L}$
Froude number
4. e
coefficient of restitution
5. $l / L$
topographic geometric similarity
6. $z_{0} / \mathrm{L}$
roughness stmilitude
7. $z_{0}^{1} / L$
roughness similitude in saltation
8. $h / L$
reference height simflitude
9. $2_{0} / L^{*}$
stab1lity parameter
10. $\lambda / \mathrm{L}$
ripple length simflitude
11. $v_{F} / v_{*}$
particle property similitude
12. $v_{*} D / v$
particle friction Reynolds number
13. $v_{*} / v_{*}$
fictetion speed ratio
14. $\rho / \rho_{p}$
denstey ratio
15. $V(h) \pm / h$
time scale 
The first four of these parameters have been nuggested by Strom and Gerdel (1961) as the Bcaling parameters of primary 1taportance tn the modelIng of accumulation of wind-driven snow and could thus also be important in modeling accumulation of dust particles from dust s\%o: Some of the parameters are interrelated. The roughness height in saltation, $z_{0}^{\prime}$, for example, has been assumed by different investigators to be proportional to particle diameter (2ingg, 1953), to ripple wavelength (Bagnold, 1941), or to the square of particle terminal speed $\left(z_{0}^{0} \sim v_{F}^{2} / 8\right.$, Owen, 1964). Thus parameter 7 $\left(z_{0}^{\prime} / L\right)$ would be proportional to parameter $1\left(D_{p} / L\right)$, parameter $10(\lambda / L)$, or to the ratio of parameter 3 to the square of parameter $2\left(v_{F}^{2} / g L\right)$ In the latter case since (Bagnold, 1941)

$$
v_{*}=A \sqrt{\frac{\rho_{P} \rho_{D_{p}}}{\rho}}
$$

the parameter $z_{0}^{1} / L$ would be related to parameters 1,11 , and 14

$$
\frac{2_{o}^{\prime}}{L} \sim \frac{v_{F}^{2}}{8 L}=A^{2} \frac{\rho_{P}}{\rho}\left(\frac{D_{P}}{L}\right)\left(\frac{V_{F}}{V_{*_{T}}}\right)^{2}
$$

Some of the listed modelling parameters may be combined by using the eqiation of motion for the particle. Since the flow pattern near a crater and ii the crater wake is related to the crater diameter, the vertical equaticn of motion, for example, is made dimenstonless by using the dimensionless variables $\bar{z}=2 / D_{c}$ (whexe $z$ is the vertical displacement) and $\bar{E}=$ $V(h) t / D_{c}$. The equation becomes

$$
d^{2} \bar{z} / d t^{-2}=-3 / 4 C_{D}\left(\frac{\rho_{D}}{\rho_{D} D_{p}}\right) \bar{v}(\bar{W}-d \bar{z} / d t)-g D_{c} / V(h)^{2}
$$

where $\bar{V}$ is the dimenstonless relative speed and $\bar{W}$ the dimensionless vertical 
atr speed. Thus the dimenstonless notion is a function of the three parameters $\rho D / \rho D, V(h)^{2} / g_{c} D_{c}$, and the particle Reynolds number. c P P

Consider the model.11ng parameters:

2. ${ } D_{c} / \rho_{p} D_{p}$. By varying particle density and diameter and the crater diameter, this parameter can be varted from about 0.8 to 3 . On Mars, this parameter would vary in value from about 1 for a 100 meter diameter crater to 100 for a $10 \mathrm{kllometer} \mathrm{crater.}$

2. $V(h) / V_{F}$. Since the threshold friction speed $V_{*}$ is proportional to the reference velocity $V(h)$, providing gemmetry (Including roughness) is exactly modelled, the ratio of reference velocity $V(h)$ to terminal speed $v_{F}$ will be modelled exactly if the ratio $v_{*} / v_{F}$ is satisfled and if $\mathrm{h} / \mathrm{L}$ is satisfied.

3. $[\mathrm{V}(\mathrm{h})]^{2 / 8 L}$. The Froudc number cannot always be satisfied in the wind tunnel without having a tunnel speed far below threshold speed. It 18 desirable to make it as small as possible. Agaln since $V_{*}$ is proportional to $v(h)$, this is equivalent to requiring a modeling material with as small a threshold speed as possible. The value of this parameter varies from 10 to 150 in the wind tunnel, and from approximately 20 for a 100 meter dianeter crater to 0.2 for a 10 kflometer crater.

4. e. The coeffictent of resititution is satisfled if model and atmosphertc matertals have equivalent elastic properties.

5. $/ / h$. Topographtc features should be saaled exactly to satisfy this criterion. At large distances upstream from the region of interest, 1t is probably only necessary to have equivalent scaled aerodynamic roughness. 
6. $z_{0} / \mathrm{L}$. The aerodynamic roughness should, in general, be to scale (Jensen, 1959). Except for those cxaters surxounded by 1.argescale ejecta or othex rough surface features, this is probably small on Mars. If the corresponding model surface in the wind tunnel 1s too smooth, 1t may be necessary to dtstort th1s parameter in order to otain a turbulent boundary layer. It is Important it the same time, to insure that the ratio $h / \mathrm{h}$ be satisfled.

7. $2 J_{0} / D_{c}$. If the equivalent roughness height in soitation $z_{0}^{\prime}$ is proportional to particle dlameter, this parameter obviously cannot be satisfied on the laboratory scale mode1, since such fine particles would have a very high threshold speed. Also, if Introduced into the air stream, the particles would yo into suspension and the saltation process would not occur. Calculations of saltation trajectory, however, show that the maximum helght during saltation would be. several times larger on Mars than on Earth, Just as the saltation height on Earth is several times as large $I_{n}$ alr as $1 t$ is in water. If the equivalent roughness $z_{0}^{1}$ is proportional to $v_{F}^{2} / 8$, then $z_{0}^{1} / D_{c}$ 1s proportional to $\rho_{p} D_{p} / p_{c}$, the Inverse of the first parameter.

8. $h / h$. The reference height $h$ at which the reference speed is measured should be located withtn the logarithmic portions of the wind tunnel and atmospheric boundary layers.

9. $z_{0} / L^{*}$. With a 'naturally' developed bouncary layer in the wind tunnel, a boundary layer velocity proftle is achteved whlch corresponds to a neutrally stratifled atmosphere, for whtch the MoninObhukov length $L^{*}$ is infintte and the ratio $z_{0} / t^{*}$ is zero. A finite 
value of $L^{*}$ is achleved in the wind tunnel by heating or cooling the floor to obtain unstable or stable stratification. Another way of obtaining a nonneutral velocity profile in the wind tunnel (but perhaps not correct modelling of turbulence characteristics) would be by means of shear fences, graded grids, or the like (Counthan, 1969).

10. $\lambda / L$. The relative ripple length may be related to $z_{0}^{\prime} / L$ and the same comments apply.

11. $V_{F} / V_{*}$ and 12. $V_{*_{T}} D / v$. As w111 be shown above, for a given condition such as for a modelling particle of diameter corresponding to minimum threshold speed, these two parameters would have the same values as for minimum threshold speed material on Mars.

13. $\mathrm{V}_{*} / \mathrm{V}_{*_{\mathrm{T}}}$. The manner in which particles are transported and, in particular, the amount of material which is moved is a function of this ratio. Thus, in order to keep $V_{*}$ as small as possible because of the froude number, the threshold friction speed of the particle should be small.

14. $V(h) t / L$. The time scale in the wind tunnel is much shorter than the time necessary for pattern development on Mars since the characteristic time is the ratio of characteristic length $I$, to reference veloctty $v(h)$. The time necessary for pattern development on Mars can thus be predicted from wind tunnel tests.

15. A Reynolds number $V(h) l . / v$ may or may not be an important mode11lng parameter. For turbulent flows over sharp-edged features, the flow is relatively Independent of Reynolds number. The critical. model Reynulds number (above which effects are independent of 
Reynolds number) depends upon model shape. If the model is too streamlined so that the test Reynolds number is below the critical, the model may have to be distorted by roughening the surfacc, creating sharper edges, etc. In order to lower the critical Reynolds number. Snyder (1972) quotes critical Reynolds number for sharp-edged cubes of 11,000 and 79,000 for a hemispherecylinder. In the current tests, Reynolds numbers based on crater diameter were generally above these values for sharp-rimned model craters.

The ifsted parameters are easier to satisfy or w1ll come closer to satisfaction in the one atmosphere wind tunnel than in the low density tunnel. Thus, for modelling aeolian features on martian topography, the low density wind tunnel should not be used. 
Adlon, G. L., Weinberger, R. K. and McClure, D. R. 1969. Martian sand and dust storm simulation and evaluation. National Aeronautics and Space Administration CR 66882 .

Arvidson, R. F. 1972. Aeollan processes on Mars: Erosive velocit1es, settling velocitles, and yellow clouds. Geol. Soc. Amer. Bull., v. 83, p. 1503-1508.

Arvidson, R. E. In press. Wind-blown streaks, splotches, and associated craters on Mars: Statistical analysis of Marlner 9 photographs. Icarus.

Bagnold, R. A. 1941. The Physics of Blown Sand and Desert Dunes. Methuen and Co., Ltd., London, $265 \mathrm{p}$.

Bagnold, R. A. 1956. The flow of cohestonleess grains in fluids. Phil. Trans. Royal Society, A, v. 249, p. 239-297.

Bagnold, R. A. 1973. The nature of saltation and of 'bed-load' transport In water. Proc. Royal Soc. London, A, v. 332, p. 473-504.

Bidwe11, J. M. 1965. Notes on Martian sandstorms. Martin Marietta Corp. Report 1610-68-34.

Cermak, J. E. 1971. Laboratory simulation of the atmospheric boundary layer. Amer. Inst. Aeronautics Astronautics Jour., v. 9, p. 1746.

Chang, T. S., Lucas, W. C. and Youngblood, W. W. 1968. Laboratory slmulation of the Mars atmosphere, a feasibility study. National Aeronautics and Space Administration, CR-61.168.

Chep11, W. S. 1958. The use of evenly spaced hemispheres to evaluate aerodynamic forces on a soll surface. Trans. Amer. Geophysical union, ' 39 , p. 397.

Chepil, W. S. and Woodruff, N. P. 1963. The physics of wind erosion and its control. Advances in Agronomy, v. 15, p. 211-302.

Counthan, C. 1969. An improved method of simulating an atmospheric boundary layer in a wind tumnel. Atmospheric Environment, v. 3, p. 197-214.

Coanady, G. T. 1972. Geostrophic drag, heat and mass transfex coefficlents for the diabat lc Ekman layer. J. Atmosphexic Sctences, v. 29, p. 488-496.

Cutts, J. A. and $\operatorname{sith}$, R. S. U. 1973. Eollan deposits and dunes on Mars. J. Geophysical Res., v. 78, p. 4139-4154.

Davenport. A. G. and Syumov, N. 1. 1968. The application of the boundary layer wind tunnel to the prediction of wind laading. In Wind Effects on Bu11d1ngs and Structures, $v$. 1, Univ. Toronto Press. 
deVaucoulers, G. 1954. Physics of the Planet Mars. Faber and Faber Ltd., London.

Ford, E. F. 1957. The transport of sand by wind. Trans. Amer. Geophysical Unton, v. 38, p. 171-175.

Greeley, R. 19\%2. Laboratory simulation of eollan-modified craters preliminary report. Trars. Amer. Geophysical Union, v. 53, p. 427.

Greeley, R., Koscielniak, D. E. and Hodge, D. S. 1971. Bruneau sand dune fleld, Idaho, and its posstble implications in martian geology. Trans. Amer. Geophysical Union, v. 52, p. 860.

Gregory, N. and Walker, W. 1951. The effect on transition of 1solated surface excrescences in the boundary layer. Great Britain, Aeronastical Research Counc1l, Reports and Memoranda No. 2779, p. 1-23.

Halton, J. 1972. An Introduction to Dynamical Meteorology. Academic Press, pे. 87.

Jensen, M. 1958. The model-law for phenomena natural wind. Ingenibren, v. 2 , p. 121 .

Kuiper, G. P. 1957. Visual observations of Mars, 1956. Astropíns. Jour., v. 125, p. 307-317.

Lumley, J. L. and Panofsky, H. A. 1964. The Structure of Atmospheric Turbulence, Wiley, New York, 239 p.

McCa11, G. J. H. 1965. Possible meteorite craters - Wolf Creek, Australia and analogs. Annals, New York Acad of Sciences, v. 123, Art. 2, p. 970-998.

McCauley, J. F. 1973. Mariner 9 evidence sor wind erosion in the equatorial and mid-1atitude regions of Mars. J. Geophysical Res., v. 78, p. 41234137.

Malina, F. J. 1941. Recent developments in the dynamics of wind erosion. Trans. Amer. Geophystcal Unton, Pt. II, p. 262.

Murphy, J. D. and Greeley, R. 1972. Sand dunes at Eagle Cove (Bruneau), Idaho: Possible analogs to martian collan features. Trans. Amer. Geophysical Union, v. 53, p. 1035.

Murray, B. C., Soderblom, L. A., Cutts, J. A., Sharp, R. P., Milton, D. J., and leighton, R. B. 1972. Geological framework of the south polar region of Mars. Icarus, v. 17, p. 328-345.

Owen, P. R. and Ztenklewics, H. K. 1957. The production of untform shear flow in a wind tunnel. J. Fluld Mechantcs, v. 2, p. 521-531. 
P1ate, E. J. 1971. Aerodynamic characterist1cs of atmospheric boundary layexs. Atomic Energy Commission Crittcal Review Series.

Rea, D. G. 1964. The darken1ng wave on Mars. Nature, v. 201, p. 1014-1015.

Ryan, J. A. 1964. Notes on the Martian yellow clouds. J. Geophysical Research, v. 69 , p. $3759-3770$.

Sagan, C. and Pollack, J. B. 1969. Windblown dust on Mars. Nature, v. 223, p. 791-794.

Sagan, C., Veverka, J., Fox, P., Dubisch, R., Lederberg, J., Levinthal, E., Quam, L., Tucker, R., Pollack, J. B., and Smith, B. A. 1972. Variable features on Mars: Preliminary Mariner 9 television results. Icarus, v. 17, p. $346-372$.

Sagan, C., Veverka, J., Fox, P., Dublsch, R., French, R., Glerasch, P., Quam, L., Lederberg, J., Lever.thal, R., Tucker, R., Eross, B., and Pollack, J. B. 1973. Varlable features on Mars II: Mariner 9 Global Results. J. Geophysical Res., v. 78, p. 4163-4196.

Sedney, R. 1973. A survey of the effects of small protuberances on boundarylayer flows. Ames. Inst. Aeronautics Astronautics Jour., v. 11, p. 782792 .

Snyder, W. 1972. Similarity criteria for the application of fluid models to the study of air pollution meteorology. Boundary Layer Meteorology, v. 3, p. 113-134.

Stroin, G. H. and Gerdel, R. W. 1961. Scale simulations of a blowing snow storm. Proc., Inst. Environmental Science, v. 53, p. 53-63.

Sundaram, T. R., Ludwig, G. R., and Skinner, G. T. 1972. Modelling of the rurbulence structure of the atmospherfc surface layer. Amer. Inst. Aeronaut 1cs and Astronautics Journa1, v. 10, p. 743-750.

Zings, A. W. 1953. Wind tunnel studies of the movement of sedimentary material. Proc. Fifth Hydraulic Conference, Bul1. 34, Univ. ILiwa Studies in Engineering, p. 111-135. 


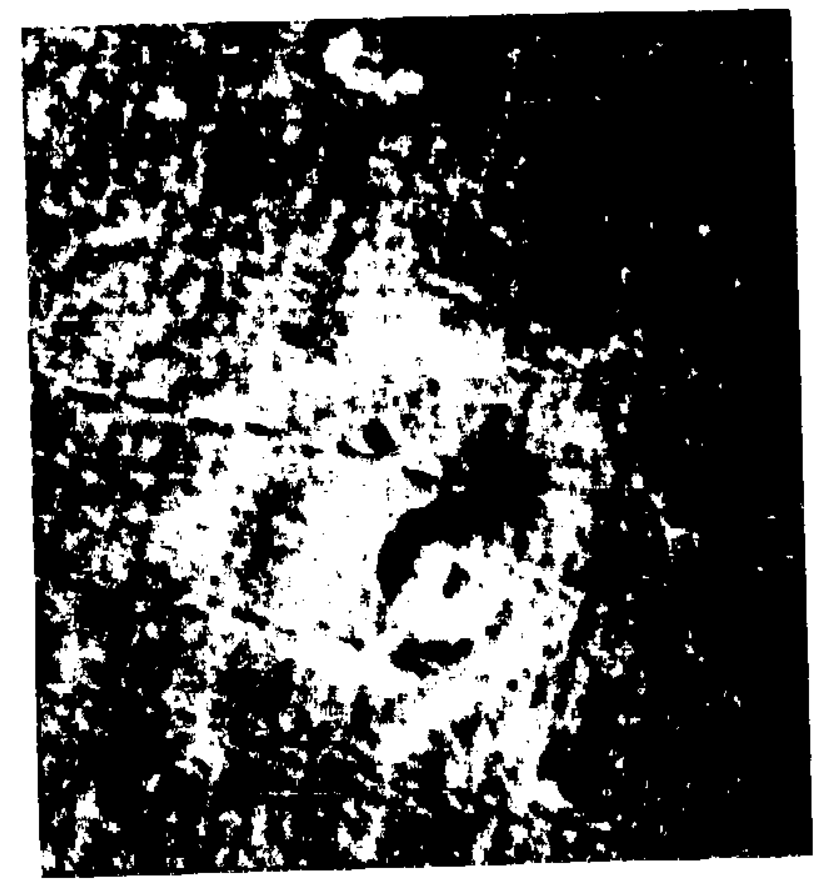



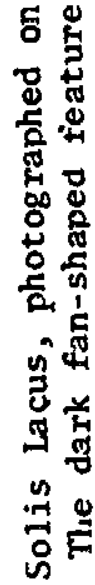

哭宾

政会

$5 N$

要

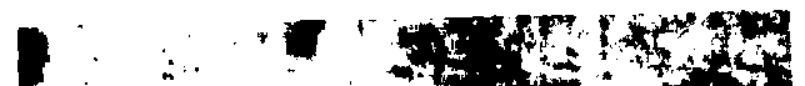

ช

要. 包

总宽

嗼

出 훙

동

出员

岂

..$\infty$

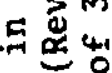

至号

둥

苛吉

훙

过跑占

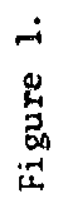




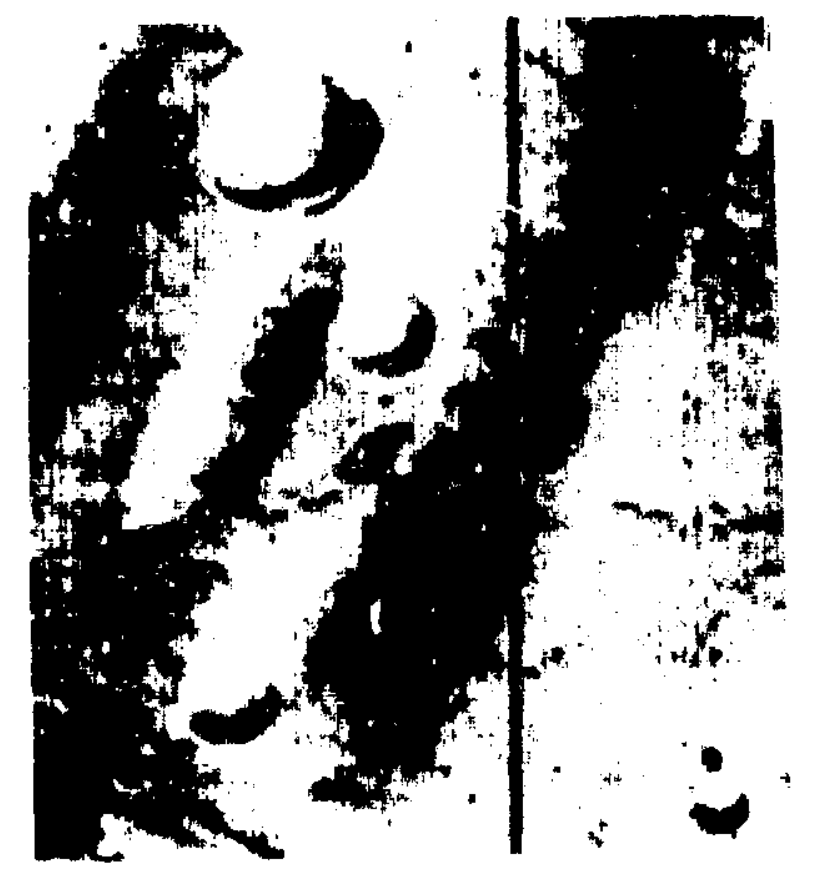

萧

舟

ค :

点些焉

ธํำ

品范

象

总苋

.

है โี

些要

웡

第

焉客

员易

5

ช

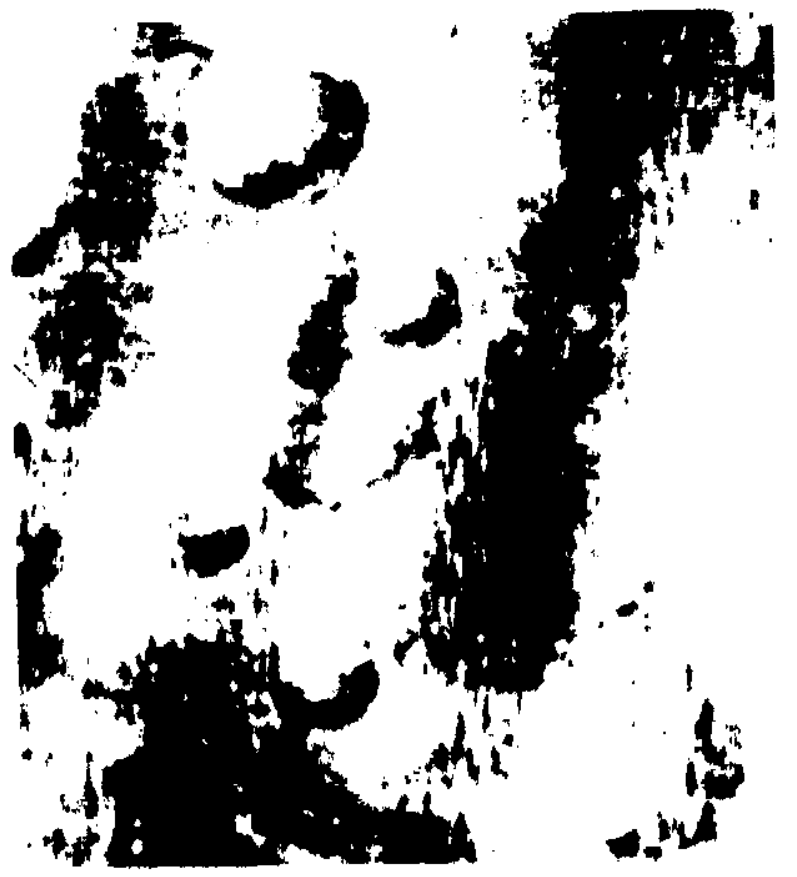

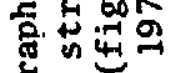

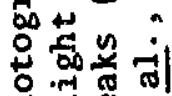

素出出

के 焉

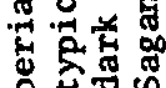

o.t.

올옹

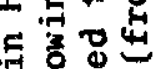

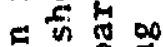

ल

可记

N

융

on

क 50

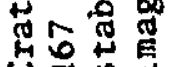

$\dot{N}$

苛 


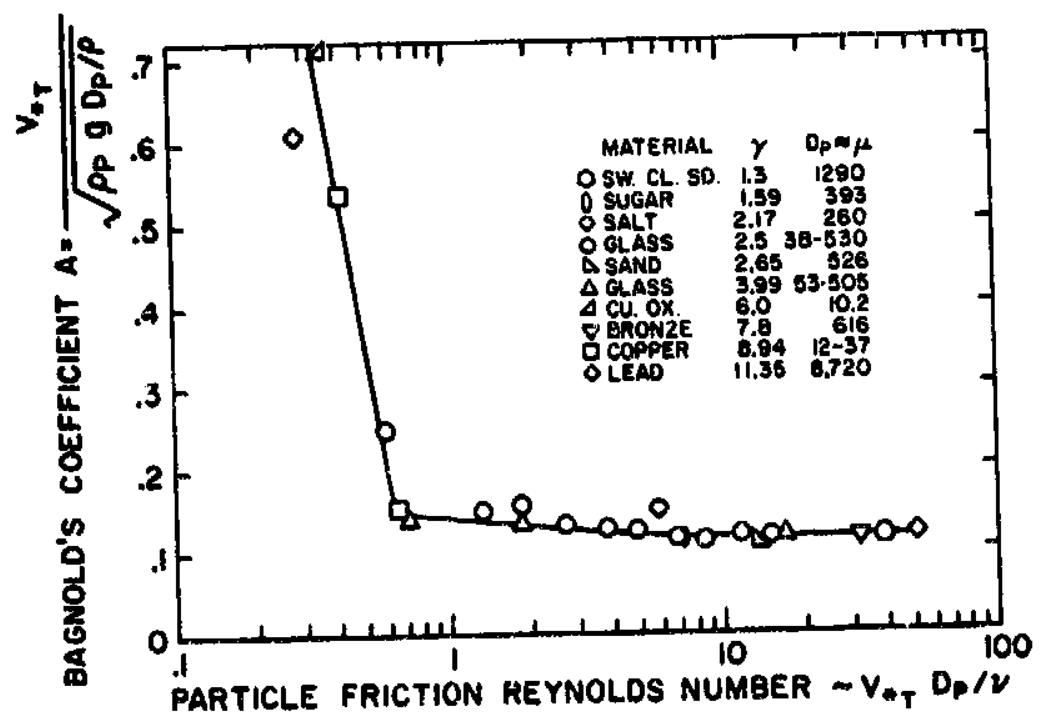

Figure 3. Threshold speed parameter ratio vs particle friction Reynolds number. SW.CL.SD. = sweet clover seed; CII.OX. = copper oxide particles. 


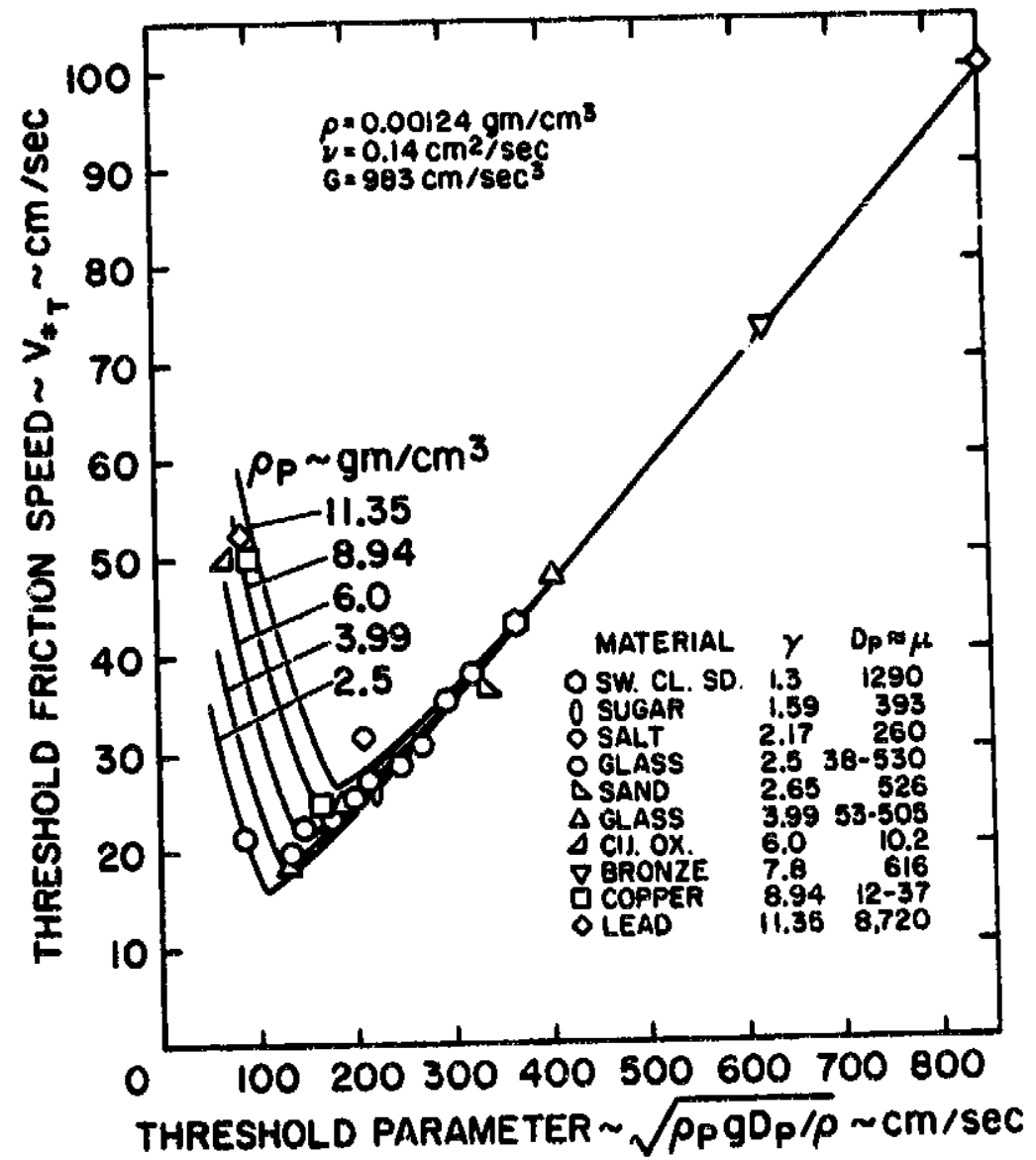

Figure 4. Threshold friction speed vs threshold parameter. SW.CL.SD. = sweet cluver seed; CU.OX. = copper oxide particles. 


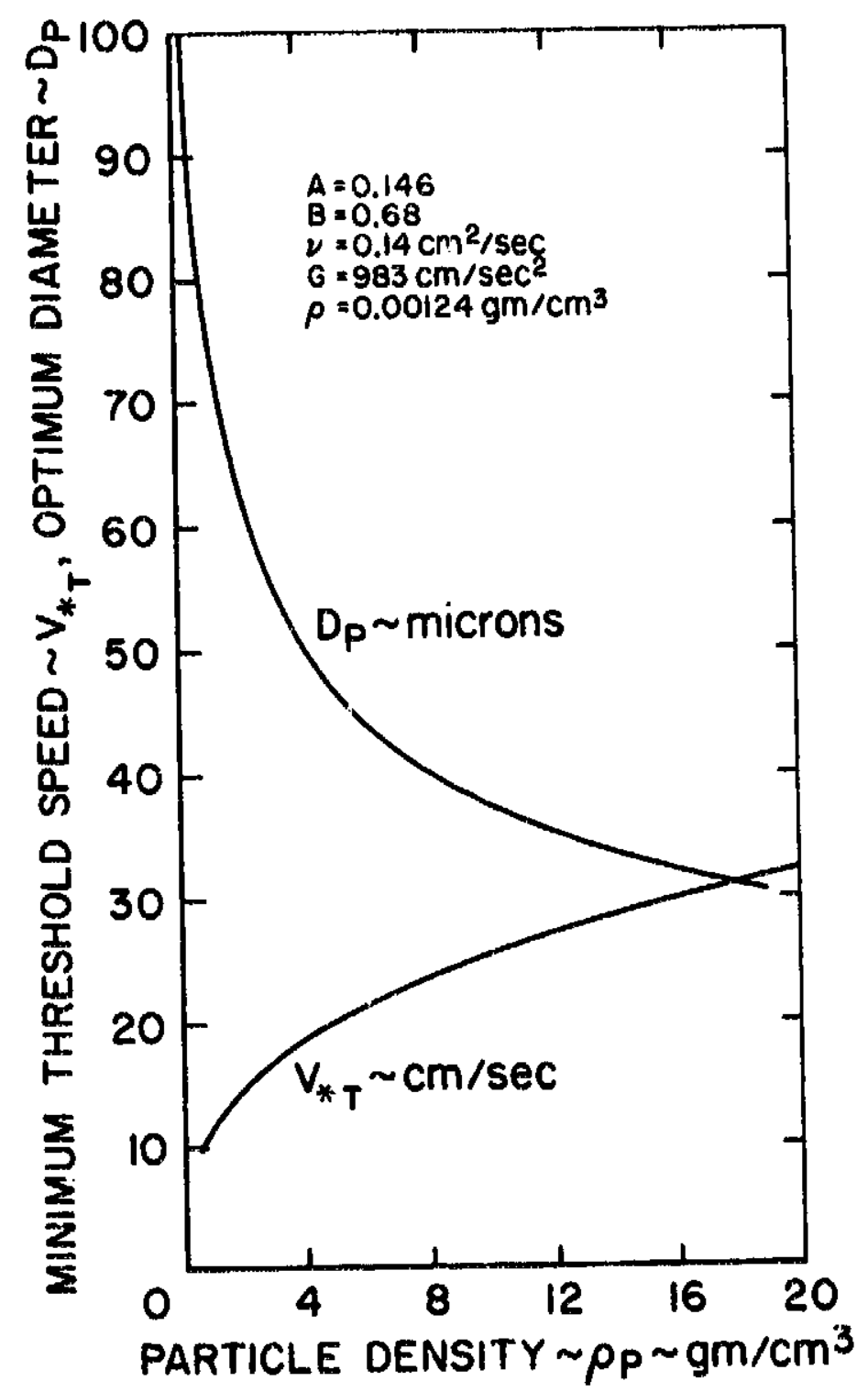

Figure 5. Variation with density of particle dianeter and threshold friction speed for minimum threshold speed. 


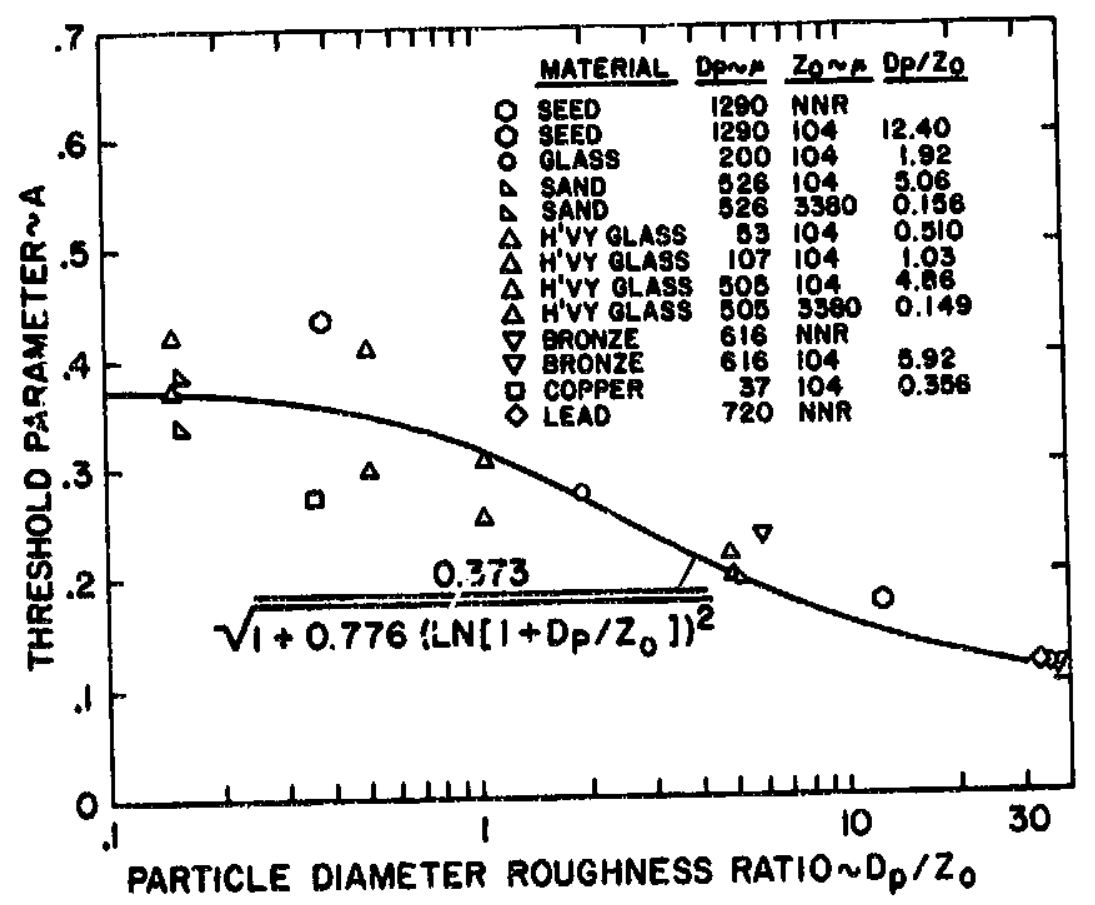

Figure 6. Threshold speed pararecer ratio vs ratio of particle dianeter to none rodible roughness i:aight. NNR = no nonerodible roughness. 


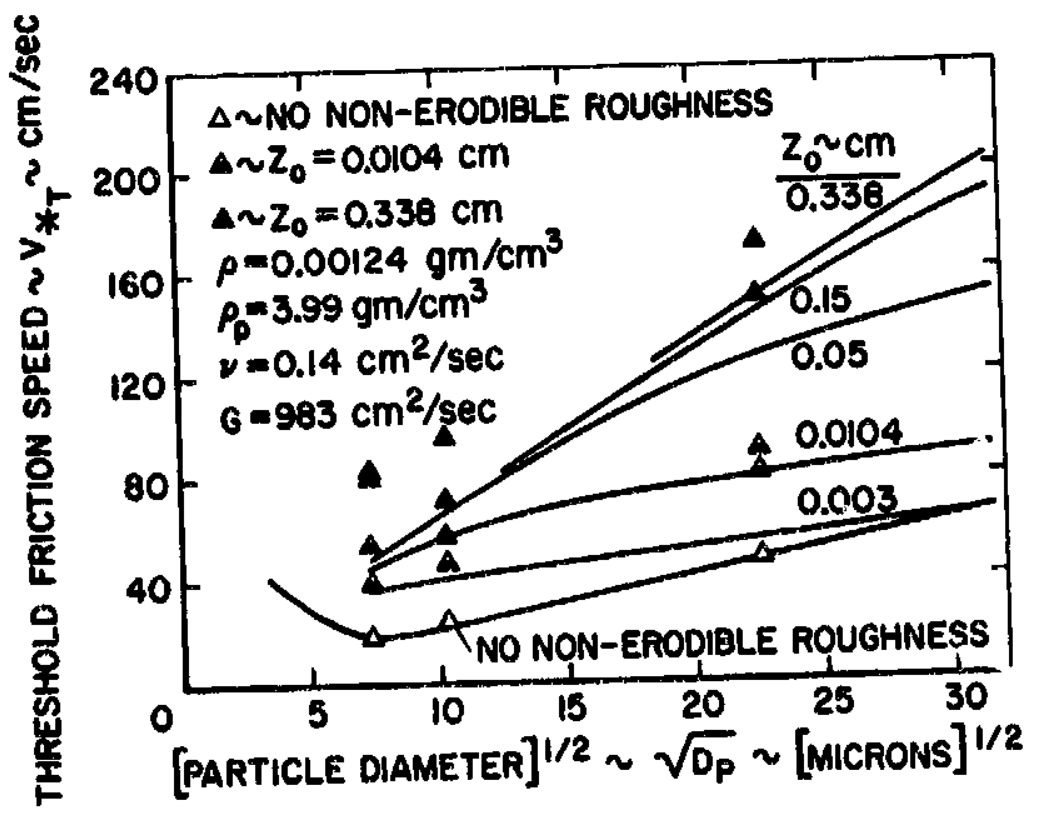

Figure 7. Threshold friction speed as a function of particle dianeter including effect of nonerodible roughness. 

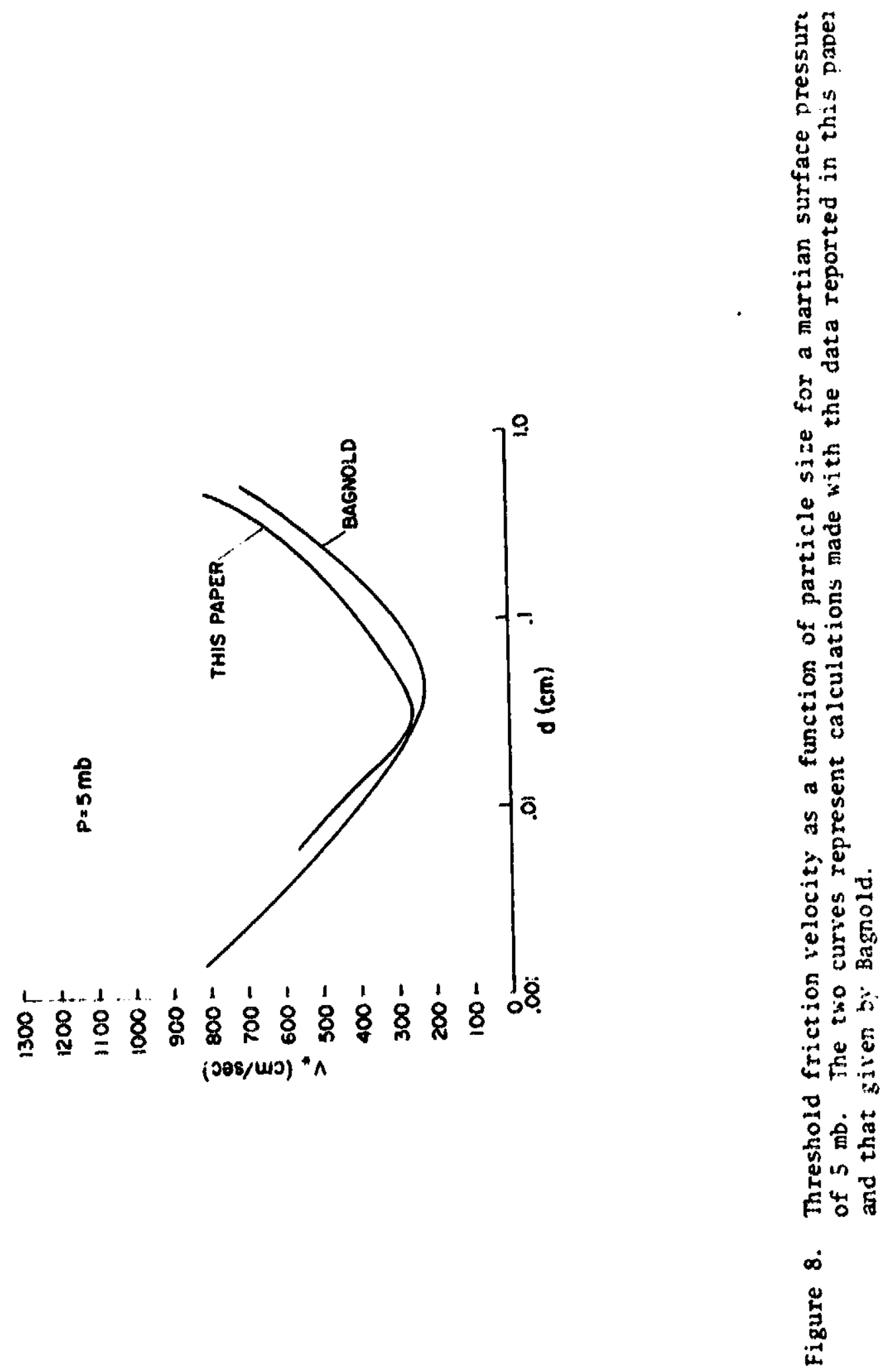


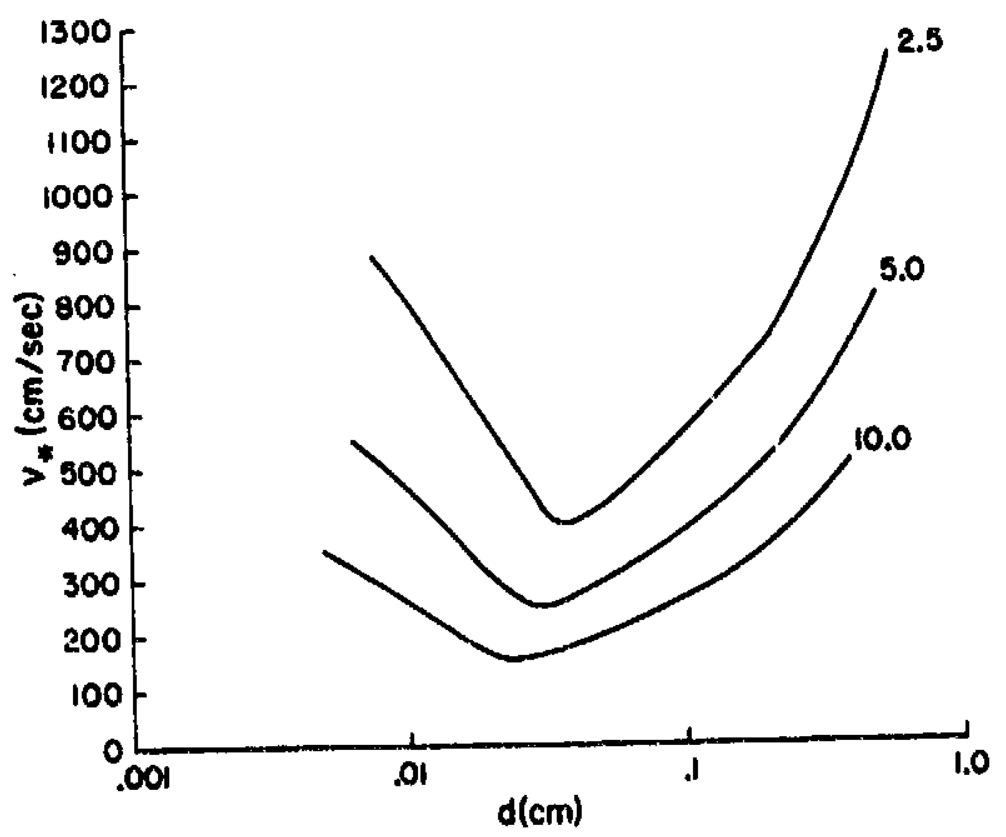

Figure 9. Threshold friction velocity as a function of particle size for mirtian surface pressures of $2-1 / 2,5$, and $10 \mathrm{mb}$. 


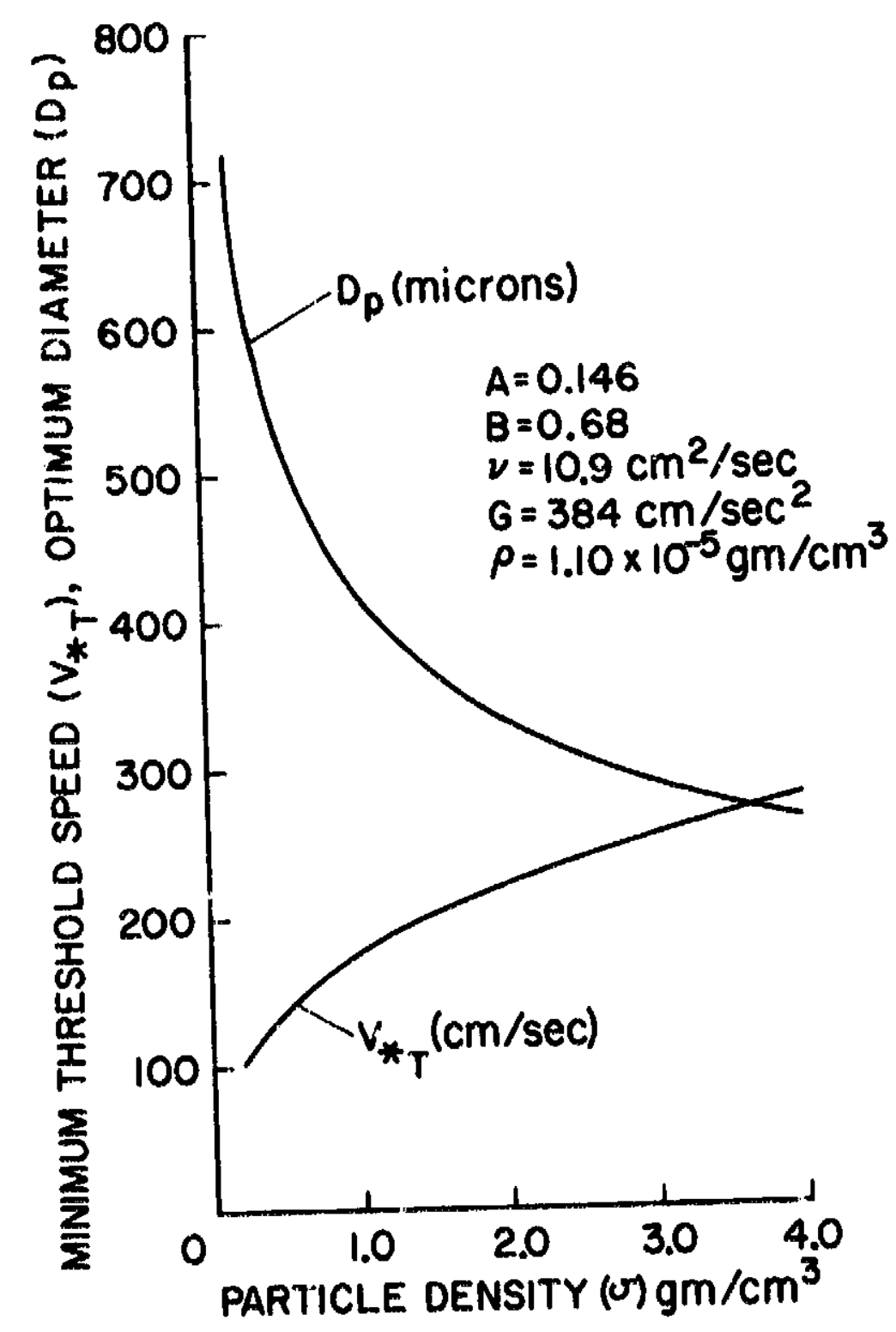

Figure 10. Harticle diameter and threshold rriction velocity ( $\mathrm{cm} / \mathrm{sec})$ as a function of particlo density as the location of the minimum in the threshold curves. The calculations were carried out for a inartian surface pressure of $5 \mathrm{mb}$. 

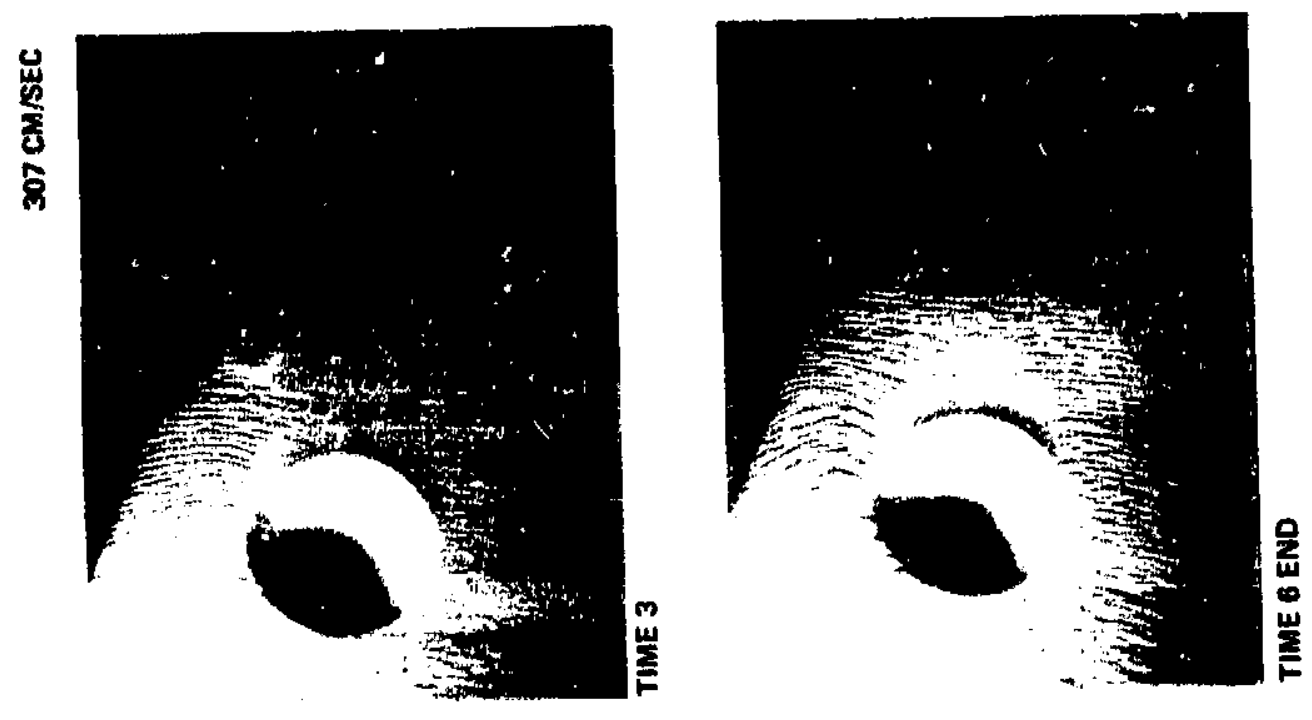

1
0
0
$n$
0
0
0
0
0
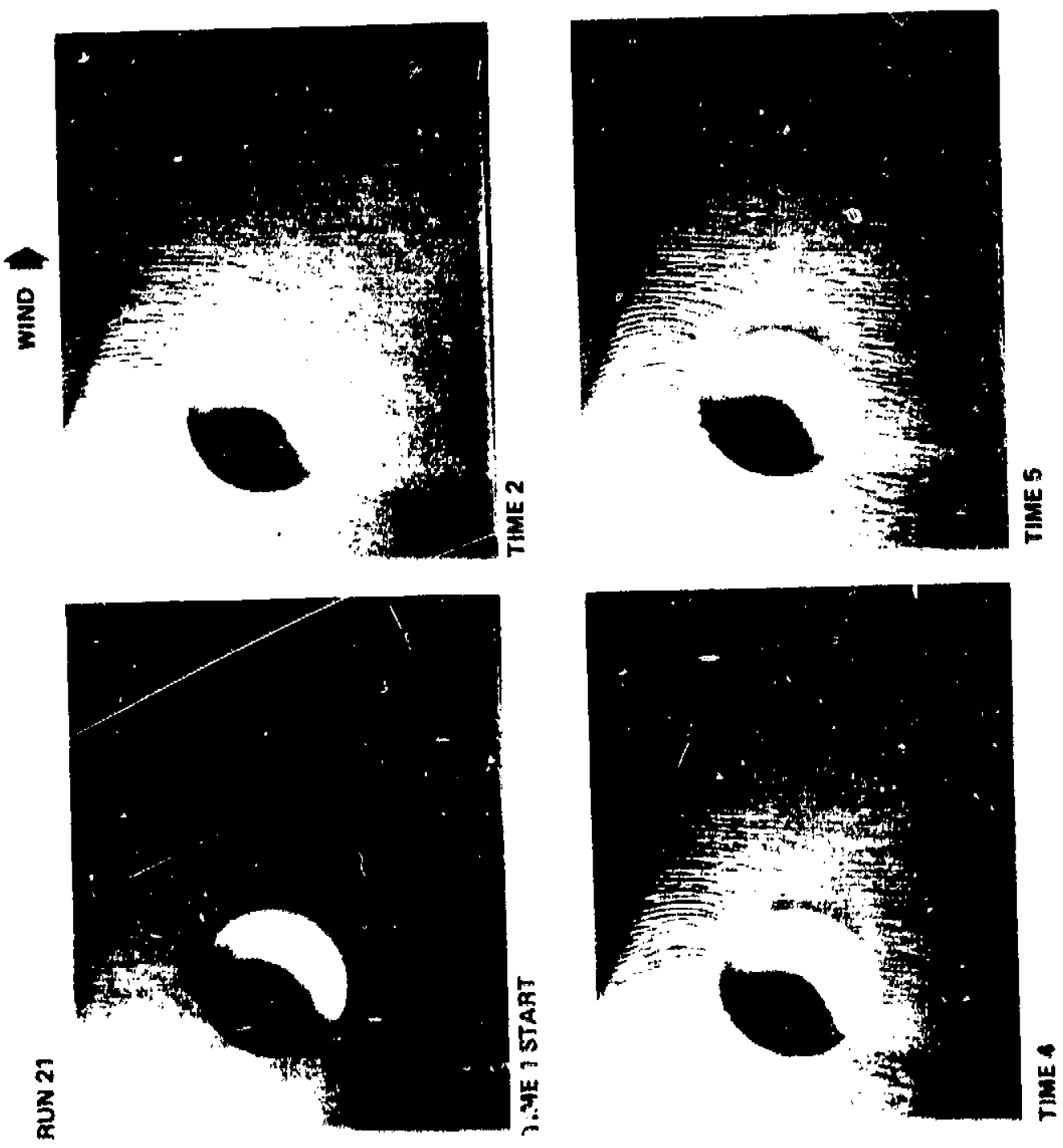

势

용

究望

홍

ता

出

है तั

온

出 䗆

出

出

究

궁

员

㟔。

동

id

롤

in 0

in $\begin{array}{r}0 \\ 0 \\ 0\end{array}$

需

总兽

3 ․ㅏㅇ

त

突

$\dot{-}$

染 

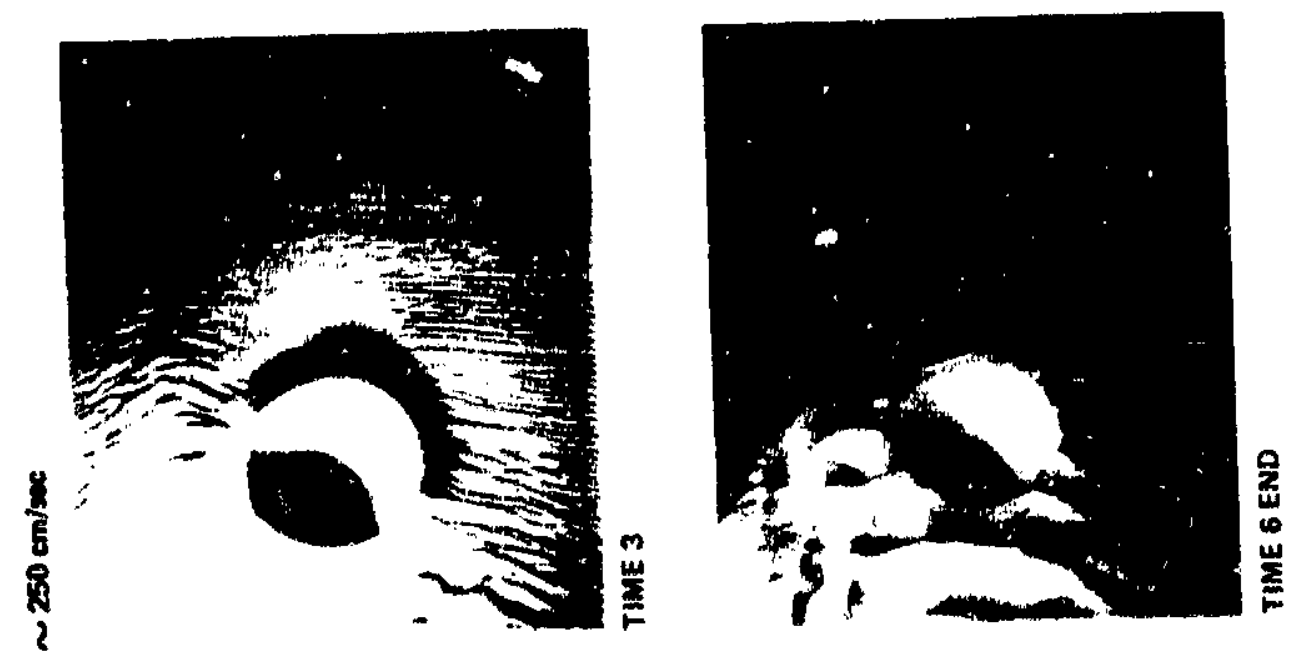

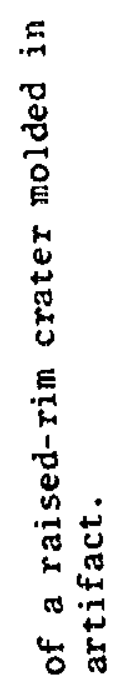
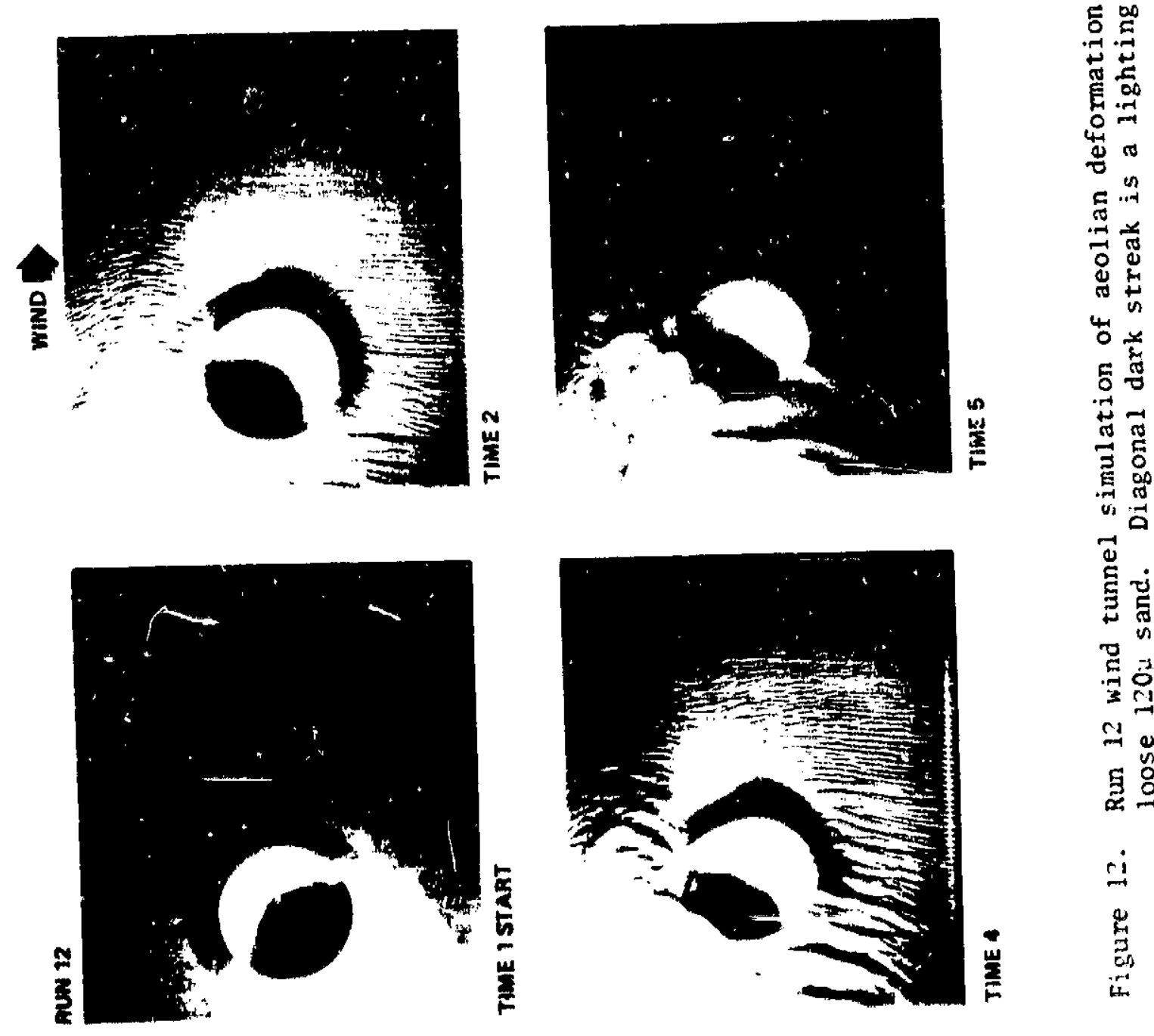

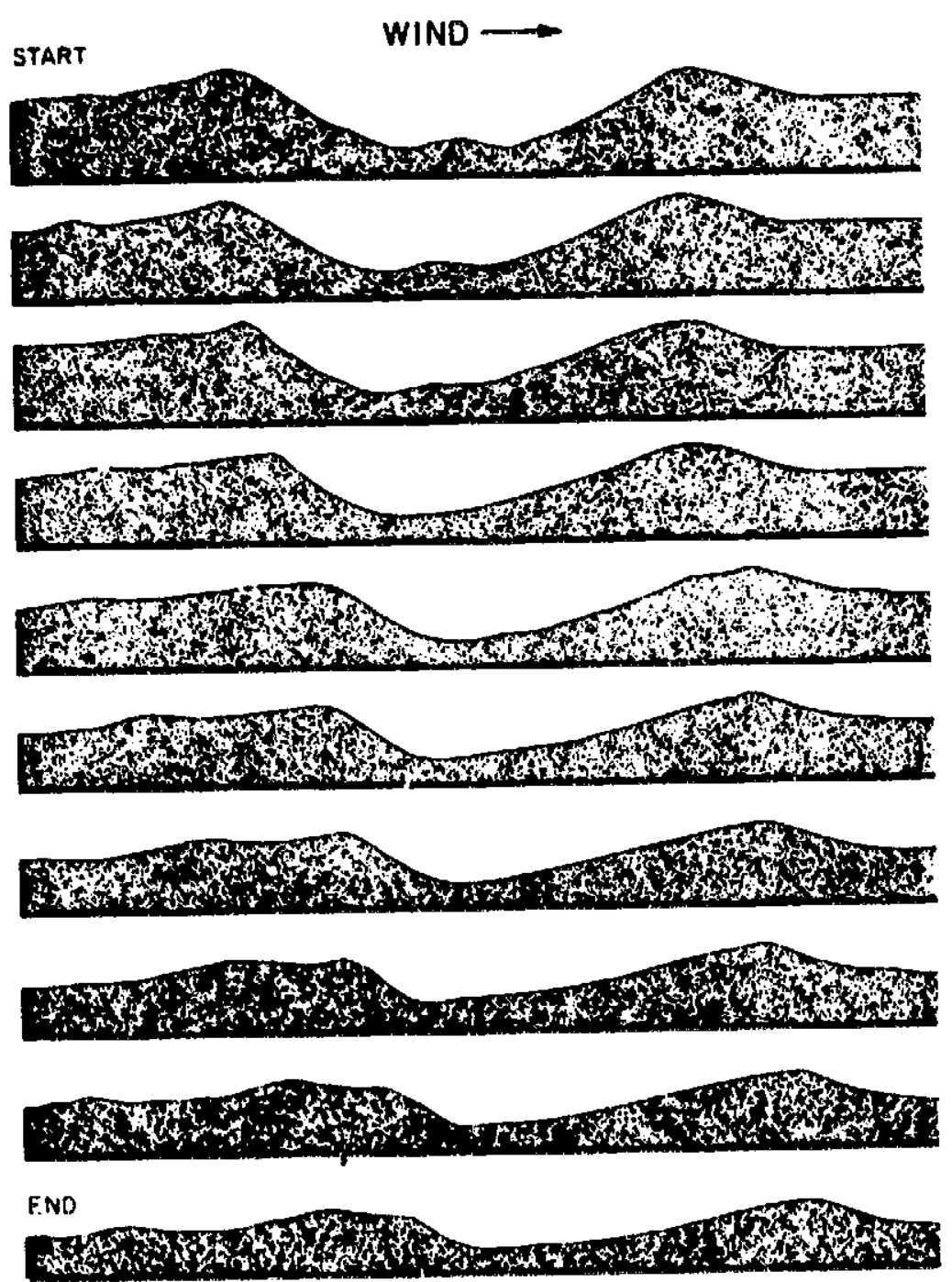

Figure 13. Sequential profiles of Run 12 (figure 12), taken parallel to the wind direction, showing: downwind migration of crater rims and relative stability of decpest part of crater floor. 

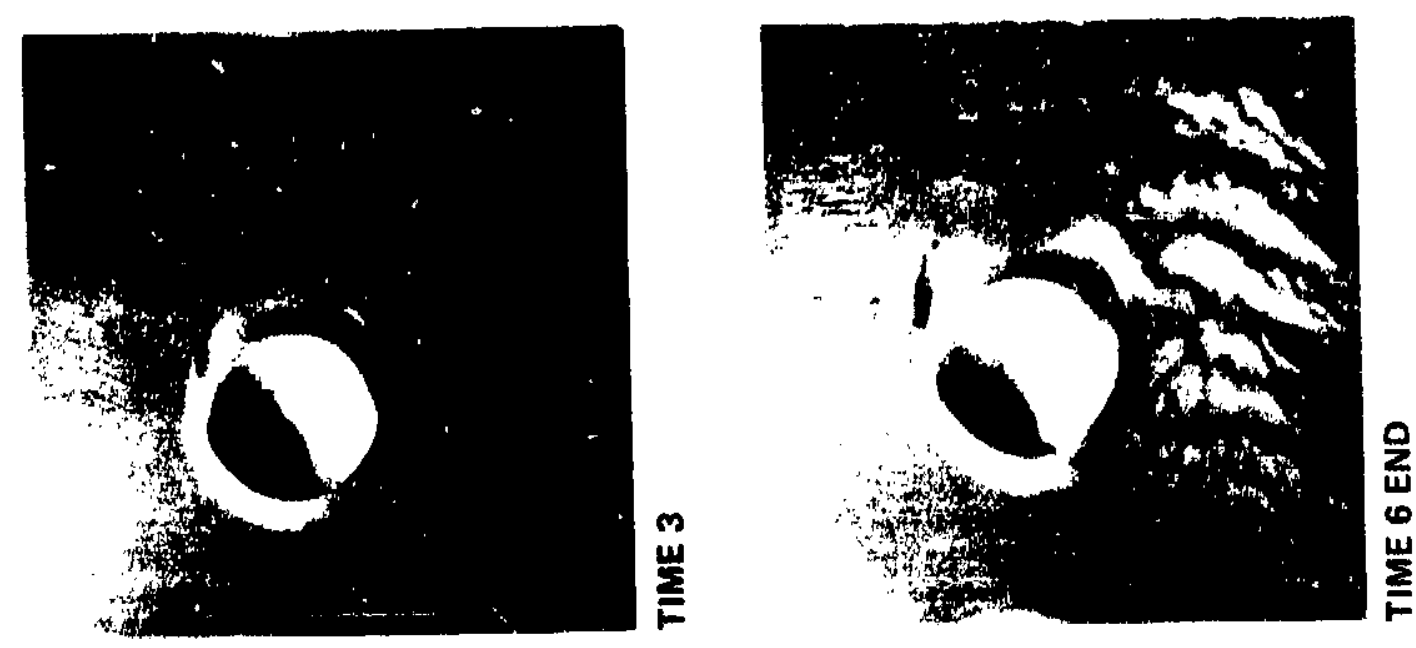

يُّ

点

丞

on

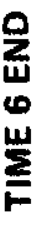
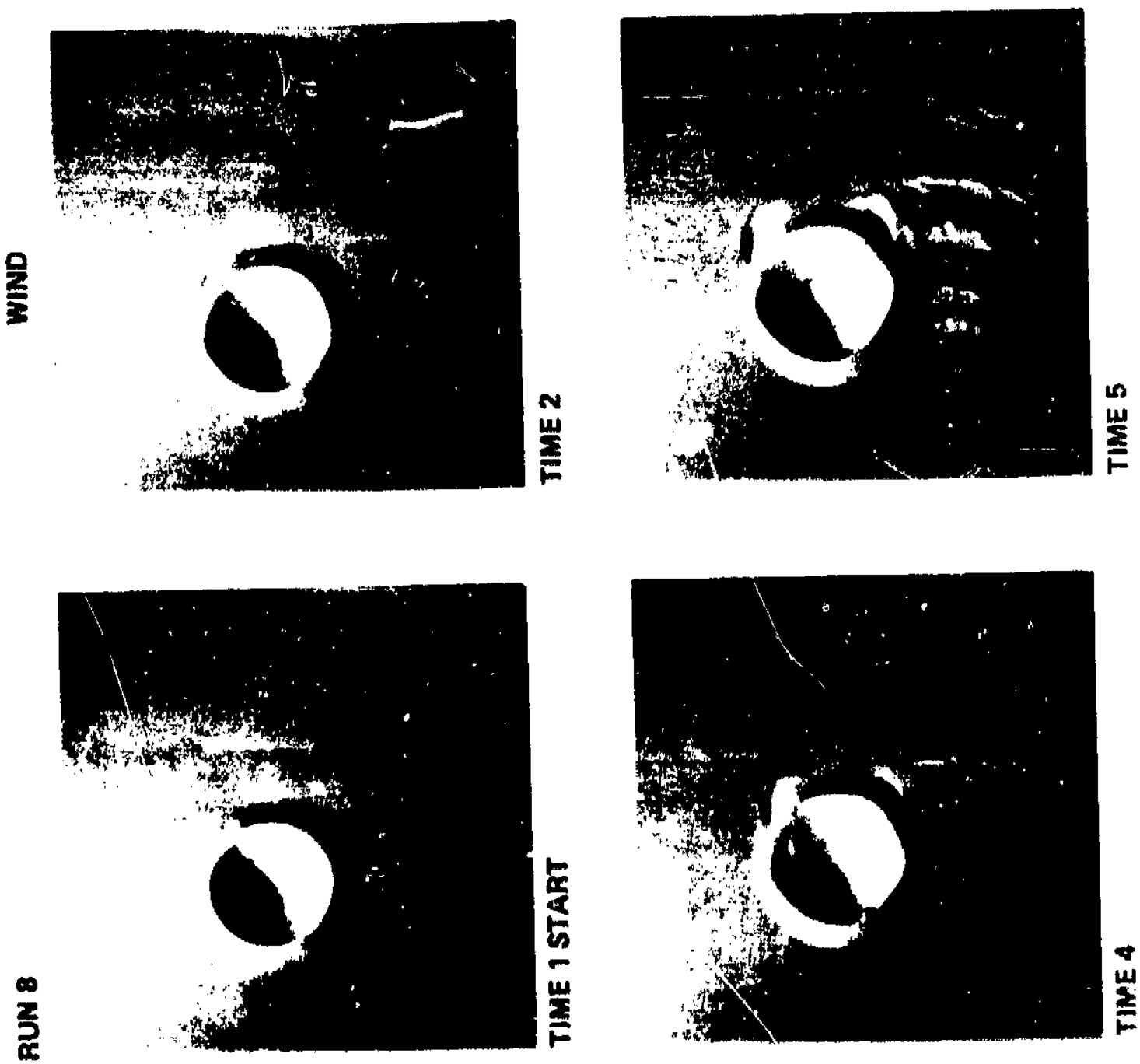

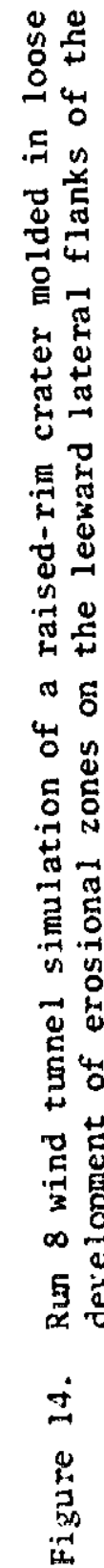




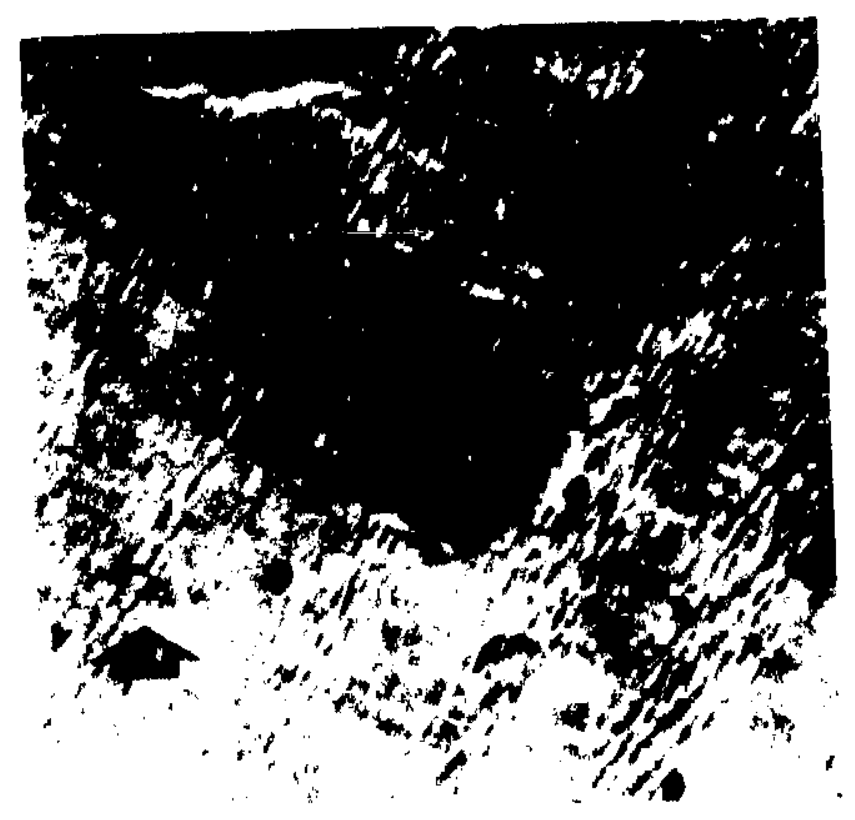

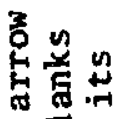

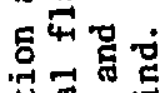

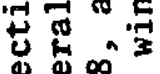

$\stackrel{\infty}{\infty}$

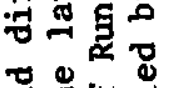

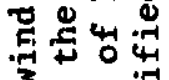

동 웡

兵䗆

害

농

A

웡

홀 월

. 5 焉

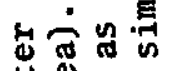

苞志菏

讨

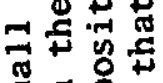

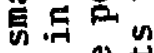

o 红点

용

于紫昰焉

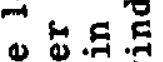

岁出焉

证告

$\infty \stackrel{4}{4}$

응 당

政 ⿷

o 4.

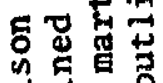

宸导叮

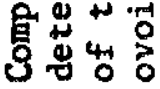

in

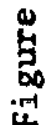



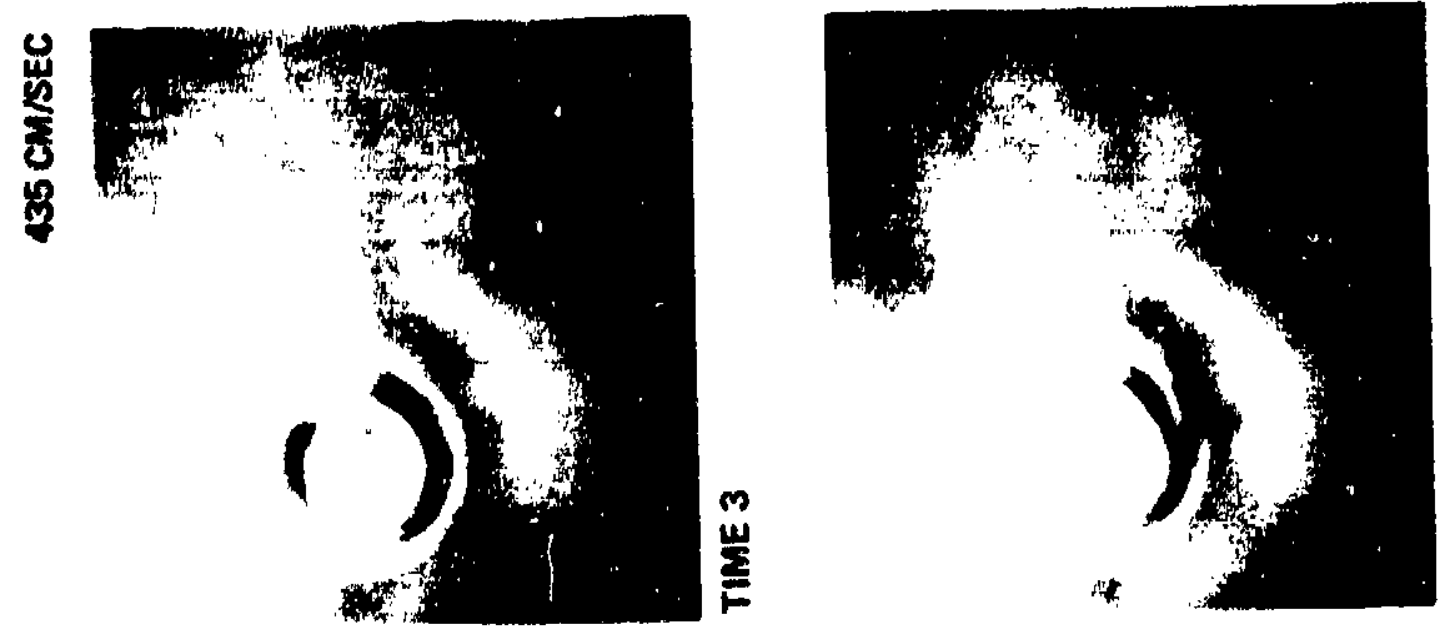

总。
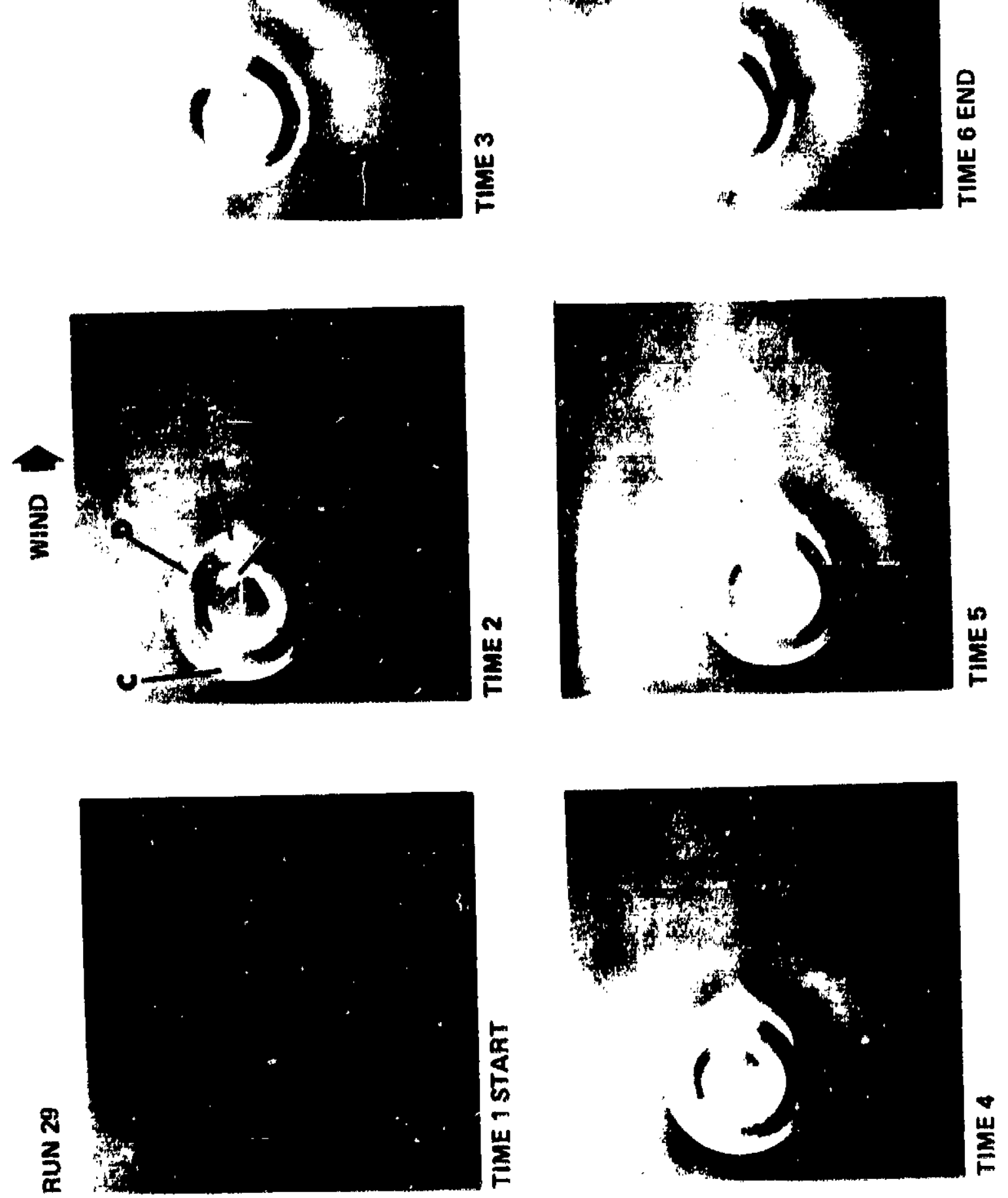

oै मै

¿

5

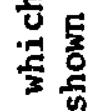

วิ

호

욤

$+\stackrel{0}{-1}$

0. प4

5

雭

旅

.7

हี

D.

雪

है ङ

嗐

可施

$\checkmark$ है

至

응 (1)

点雪晋

을

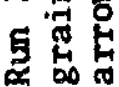

$\dot{9}$

点 


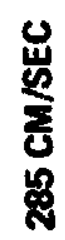
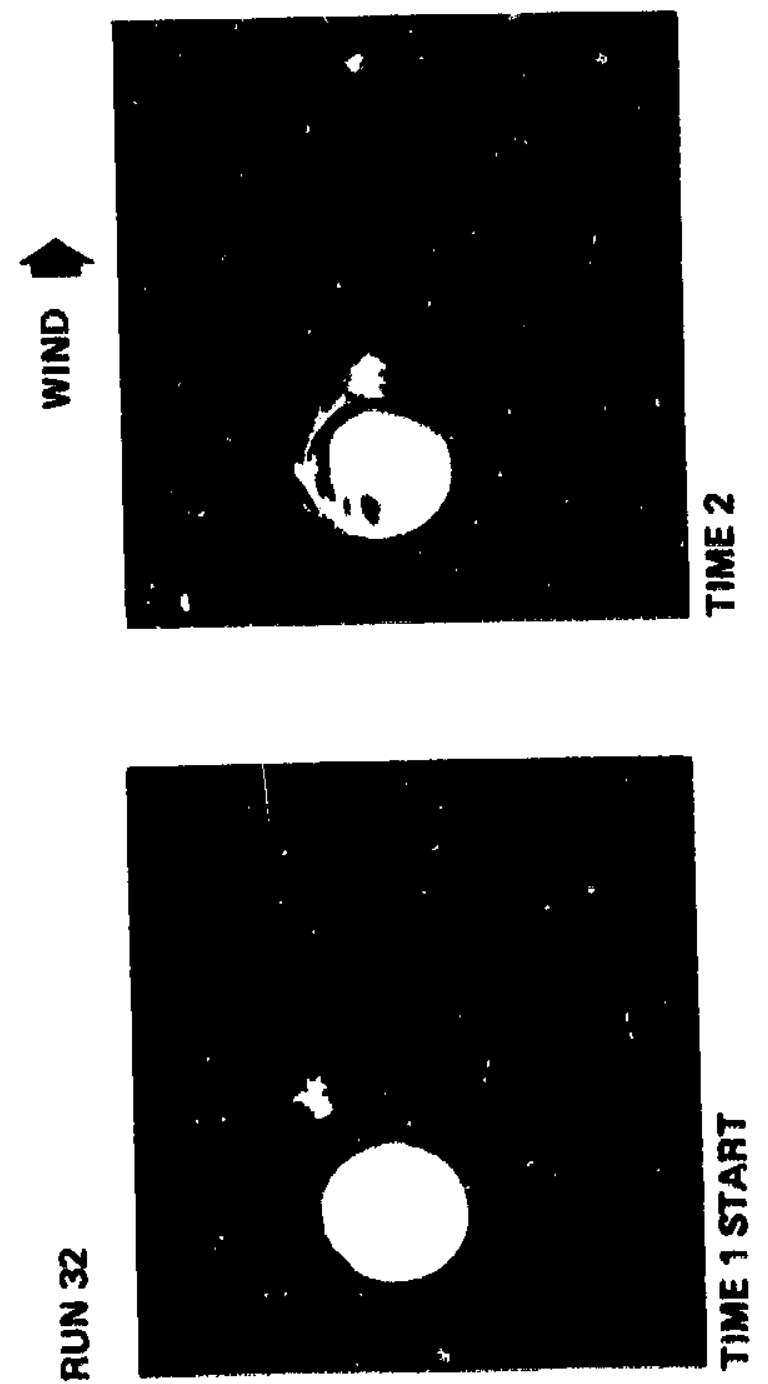

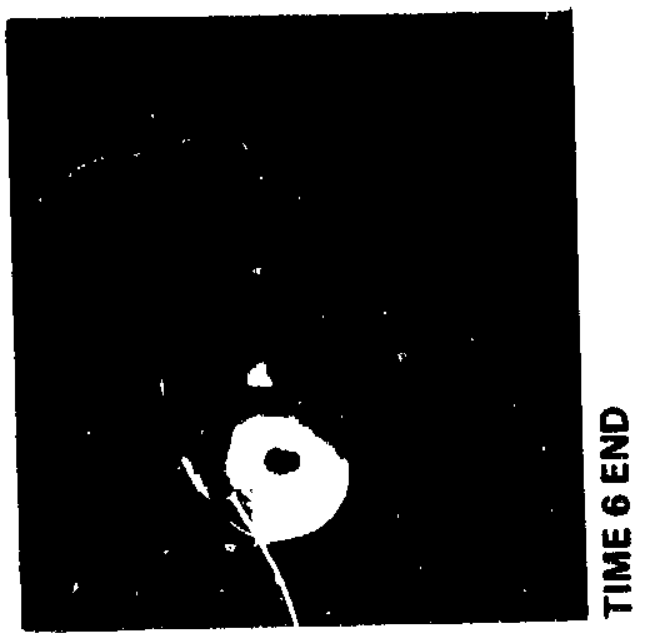

in

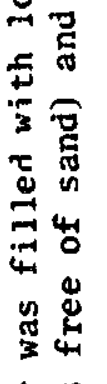

娄

包

음

s.

룽

帘苋

들.

해

。

两

要

过

蒒

其

它热

"

$\checkmark$

更

용ㅇ

मै०

ธี ฐ

กิ

㻖寄

$\therefore$

章 

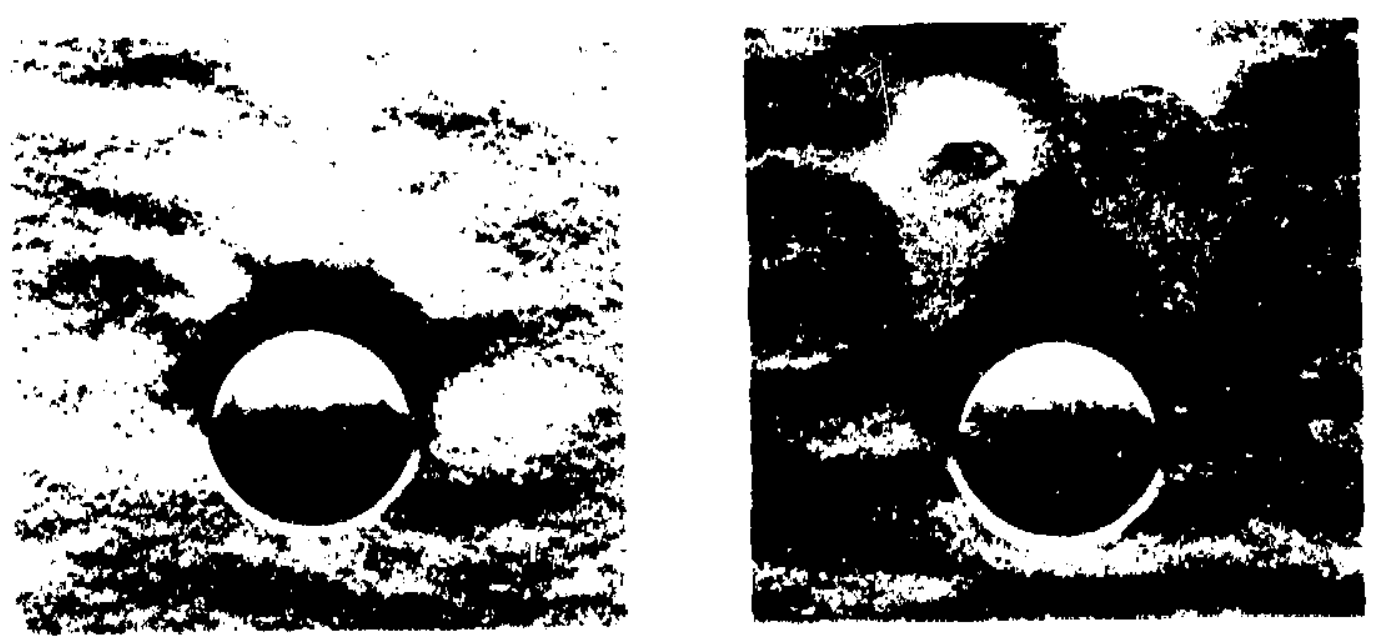

总

4t.

से के

뭉

동

至

\&.

究

氠贻

点珤

告颛

.

离

음

क

若
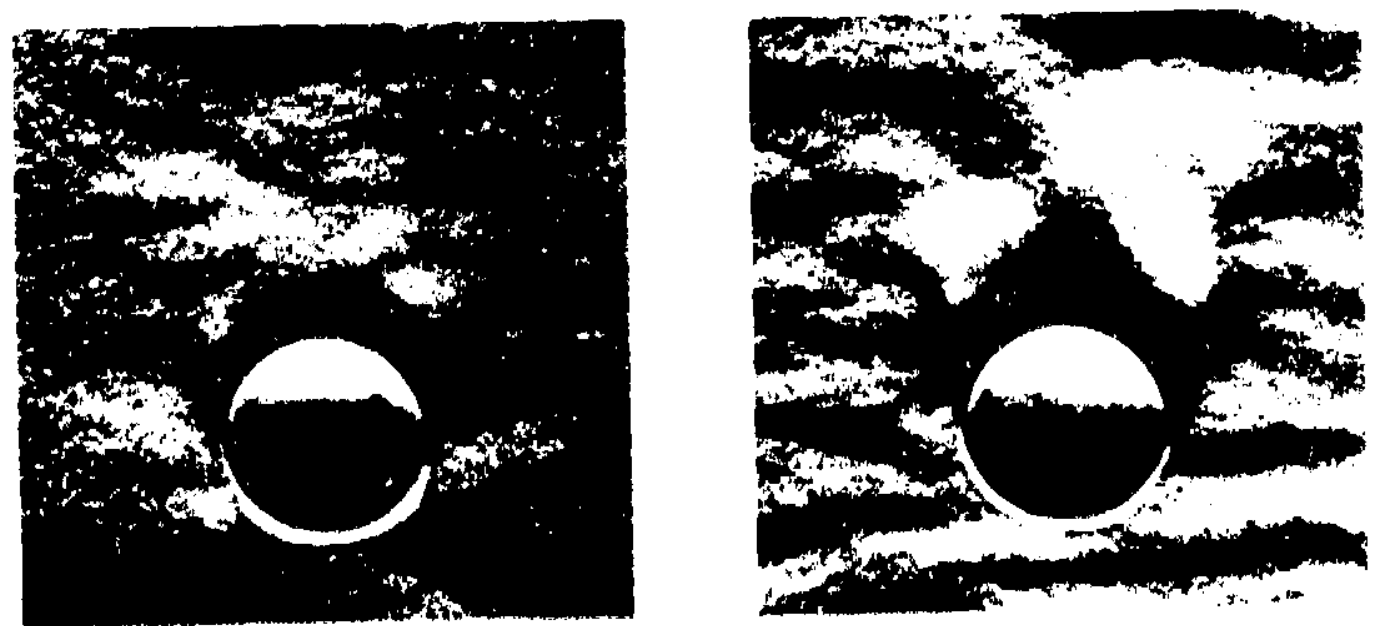

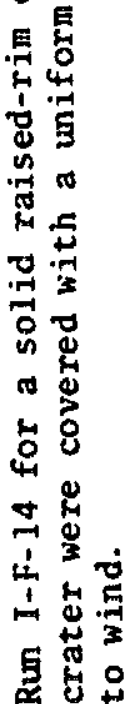

$\infty$

兽 


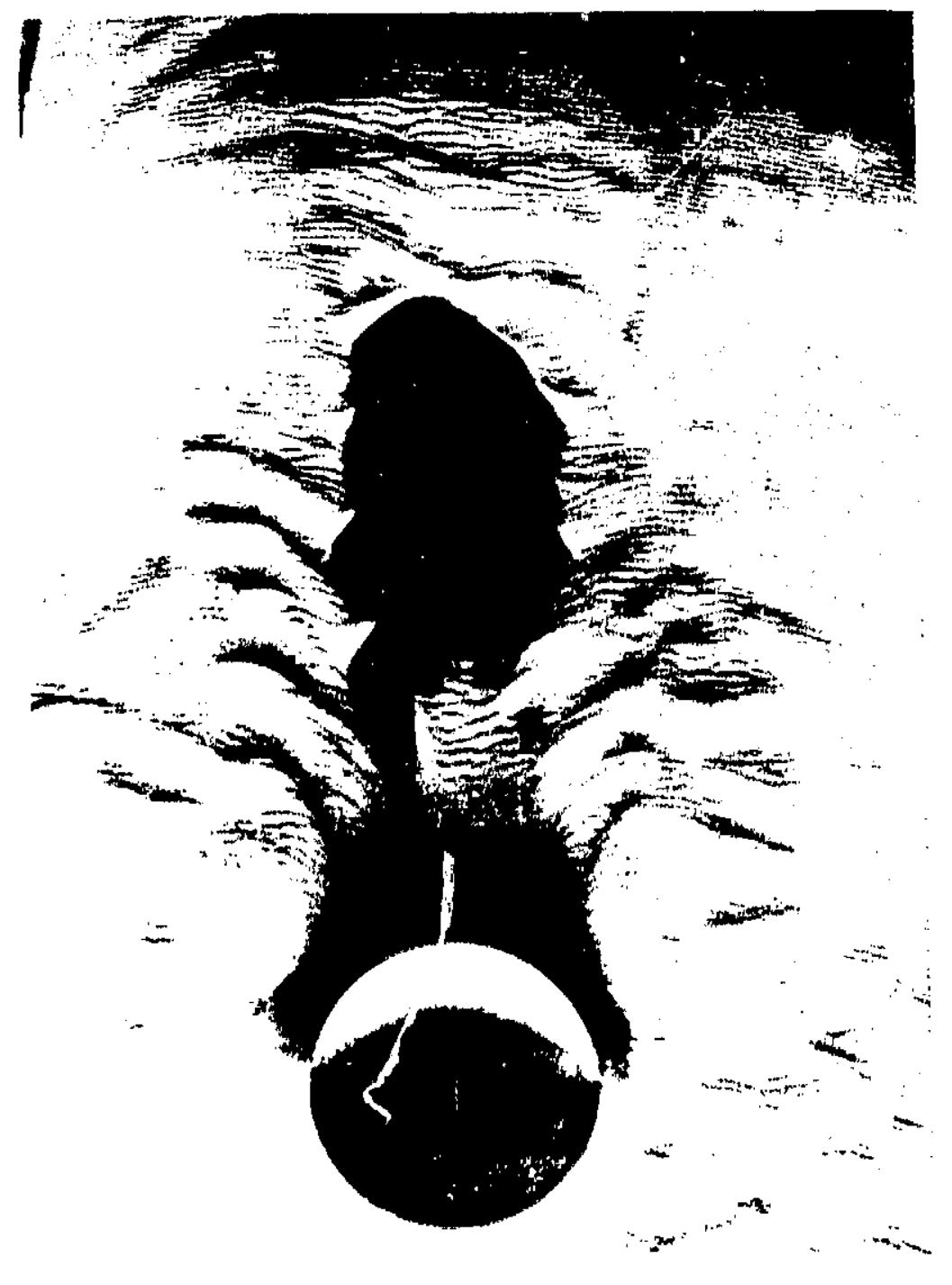

总兽

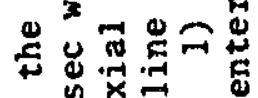

4 ज त

०

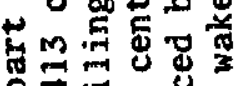

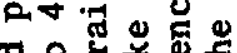

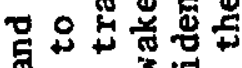

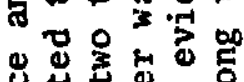

进苾

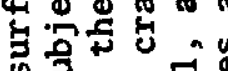

कै

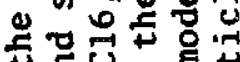

可

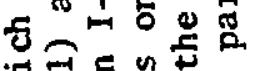

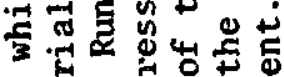

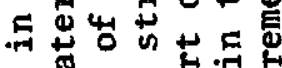

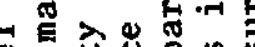

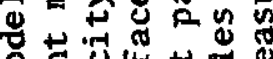

응요

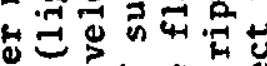

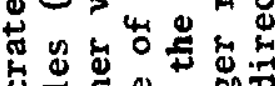

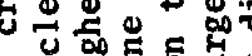

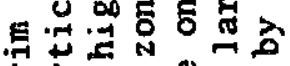

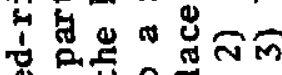
的 है?

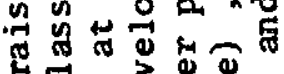

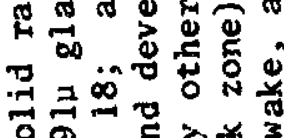

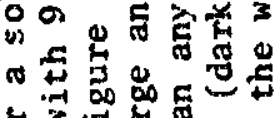

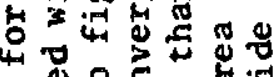
4 过

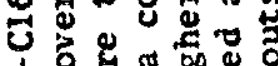
1 $8 \%$

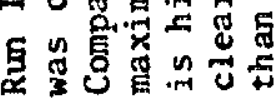

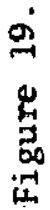



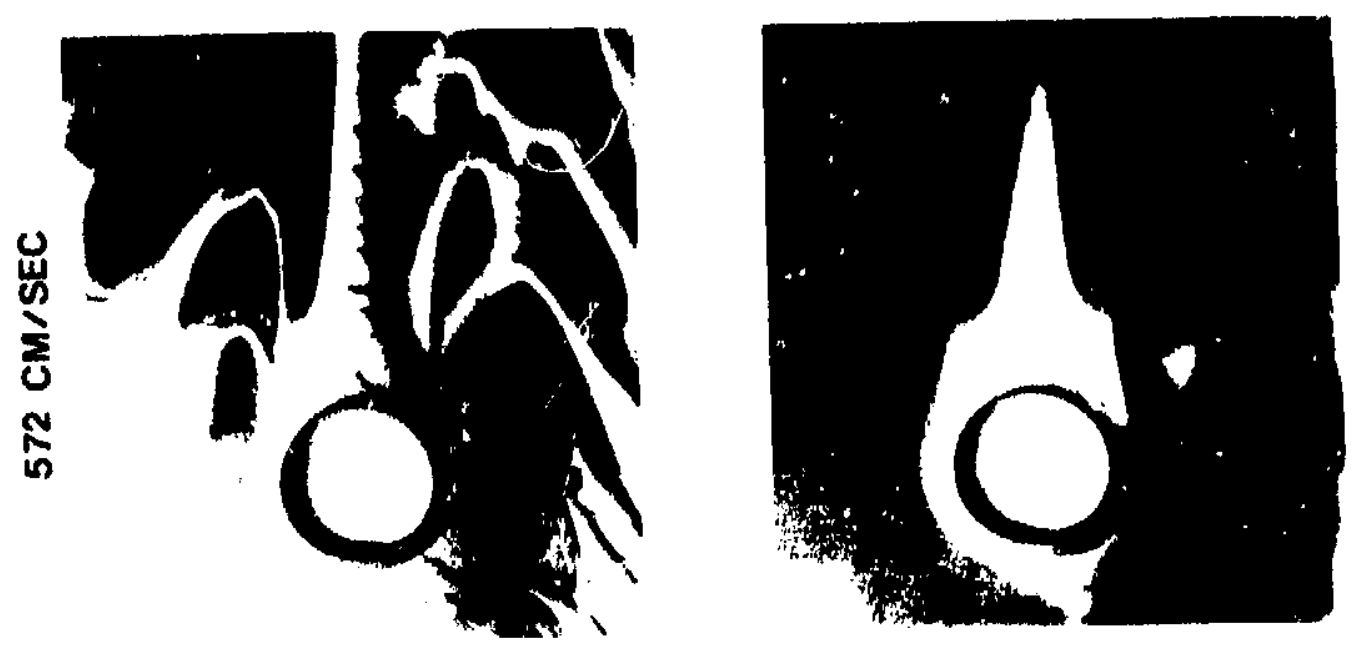

ร

岢

$\stackrel{4}{4}$

$\stackrel{\Xi}{5}$

ن

웡 궁
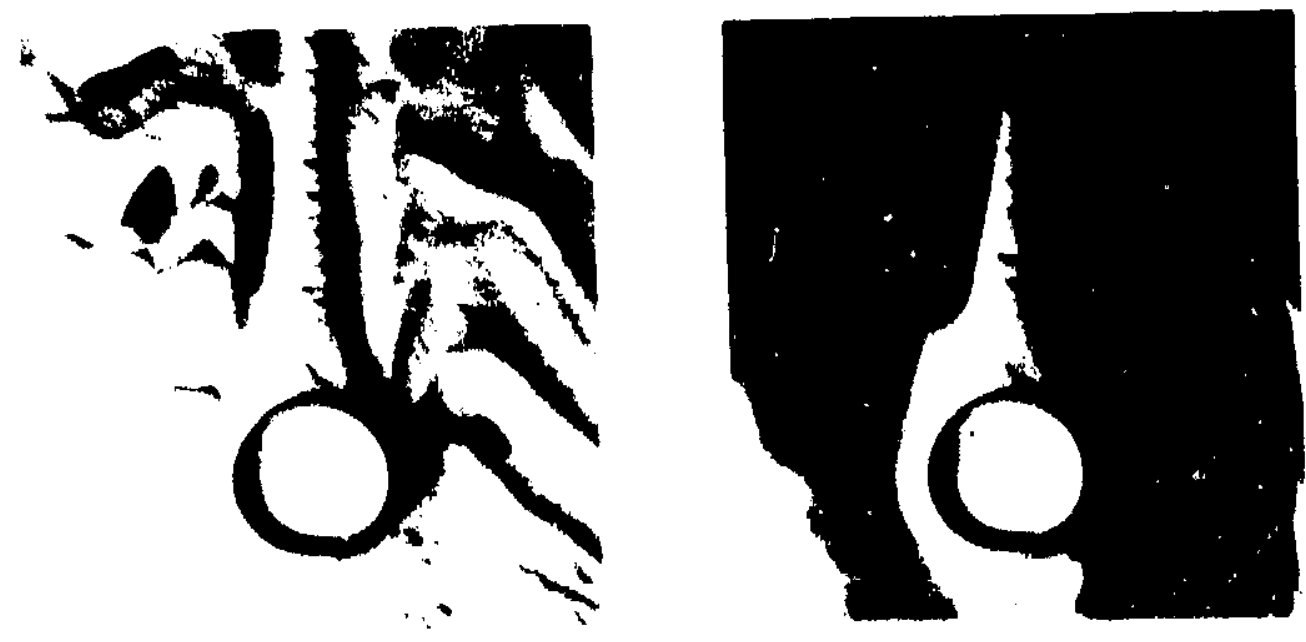

㟧

톨

ti

告

4

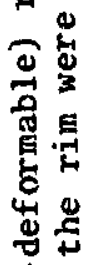

点荅

प

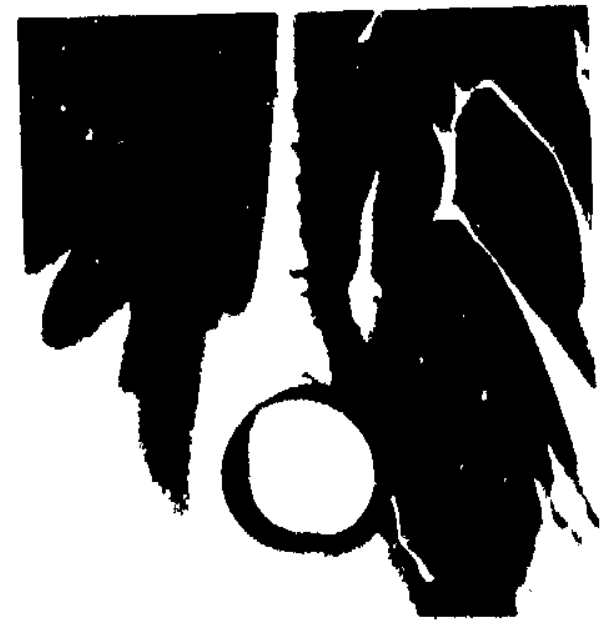

要 

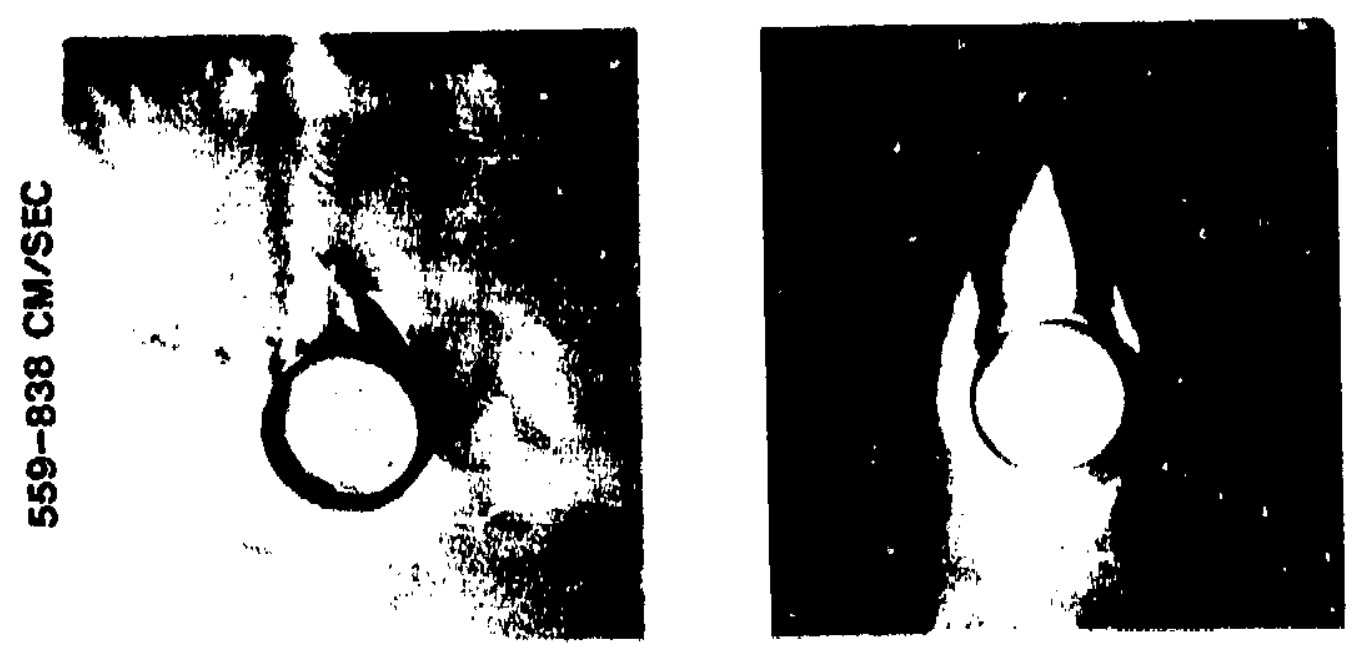

点

嚄

की
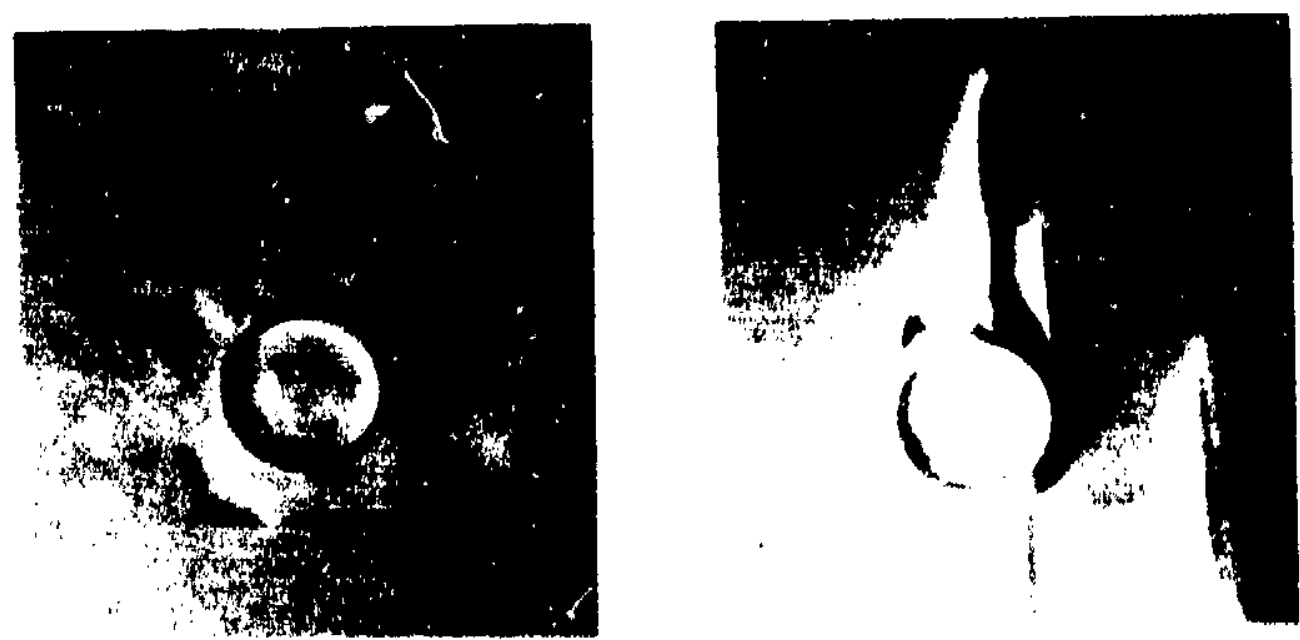

峁

it

돌

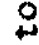

苞

点

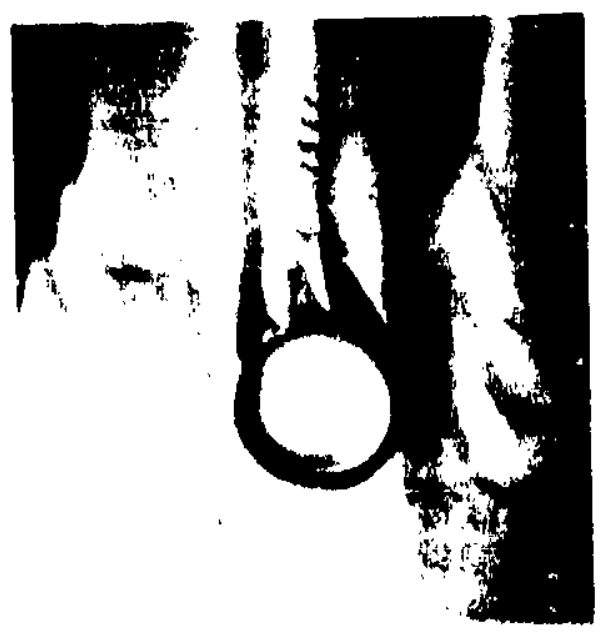

焉蛋

25

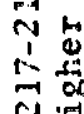

ㄷ․․

量骂

Q

( 12$)$

a.

simations

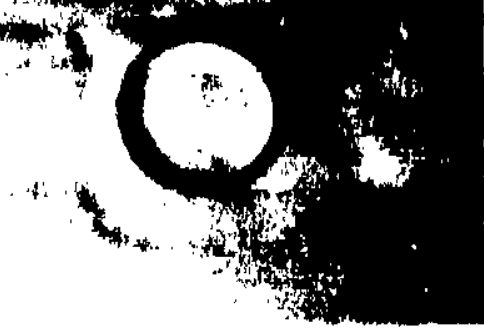

5

r.

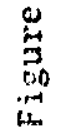




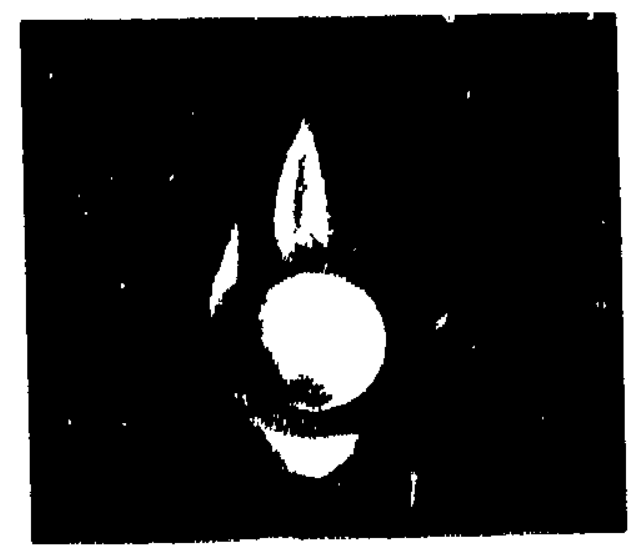

告

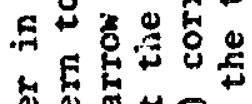
出出等各出 壳总过。 ए.

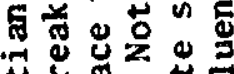

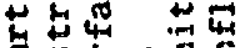
的旨它

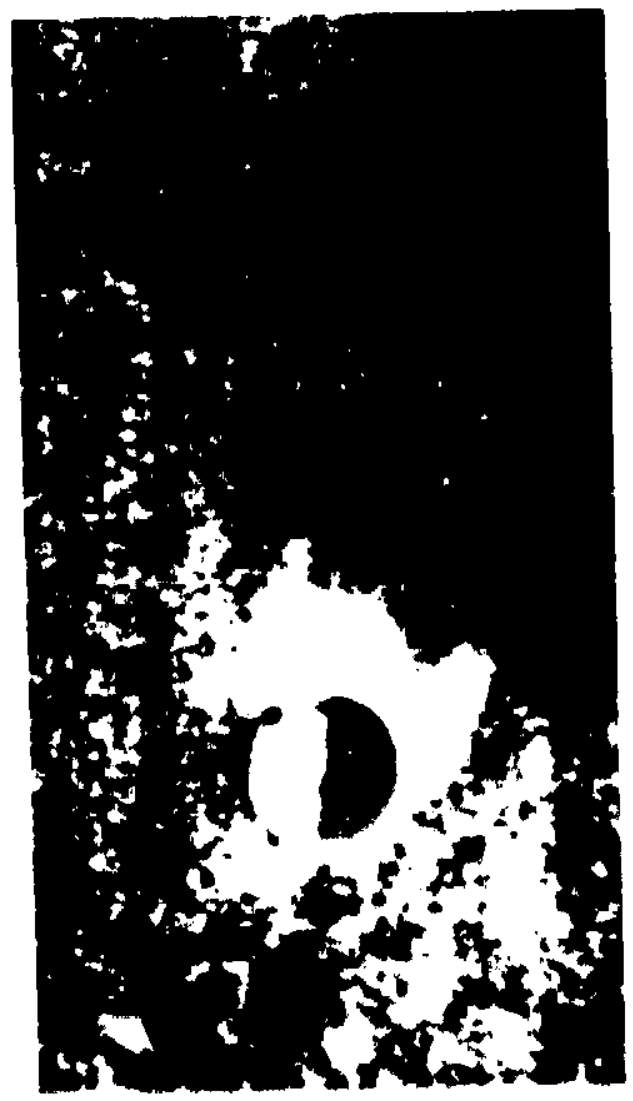

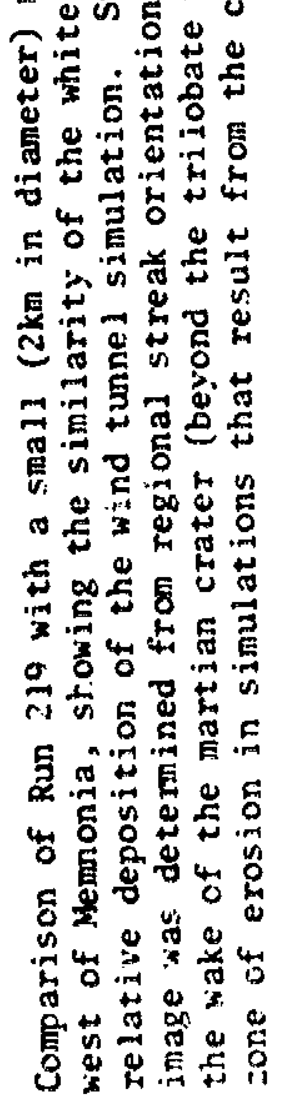

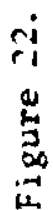


EROSION-DEPOSITION ZONES RAISED-RIM CRATER

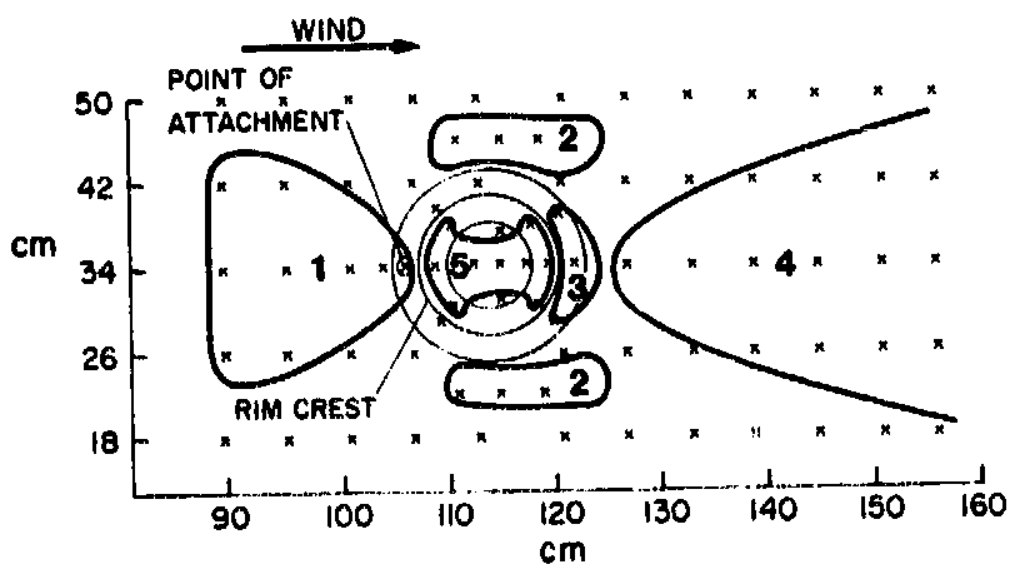

Figure 23. Diagram showing the grid layout for the threshold speed experiments to determine zones of relative erosion and deposition associated with raised-rim craters. 
FLOW FIELD AROUND A RAISED -RIM CRATER

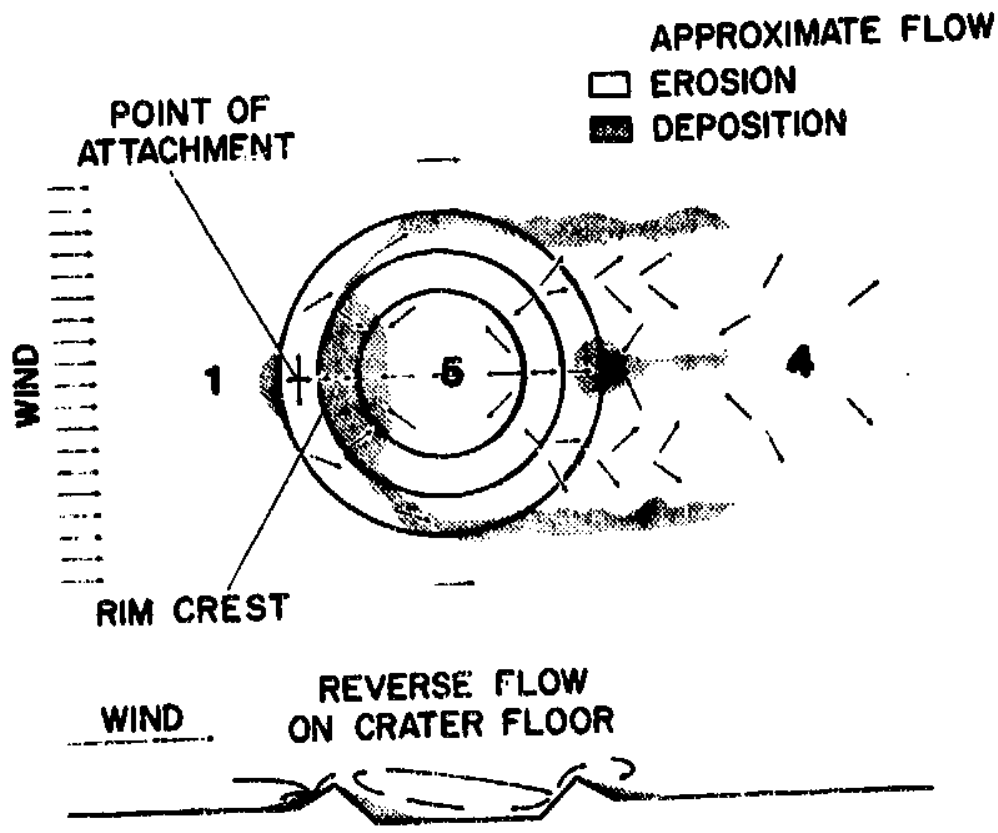

Figure 24. Zones of relucive erosion and deplosition for a raised-rim crater; arrows repx sent observed di rection of movement of sand. 


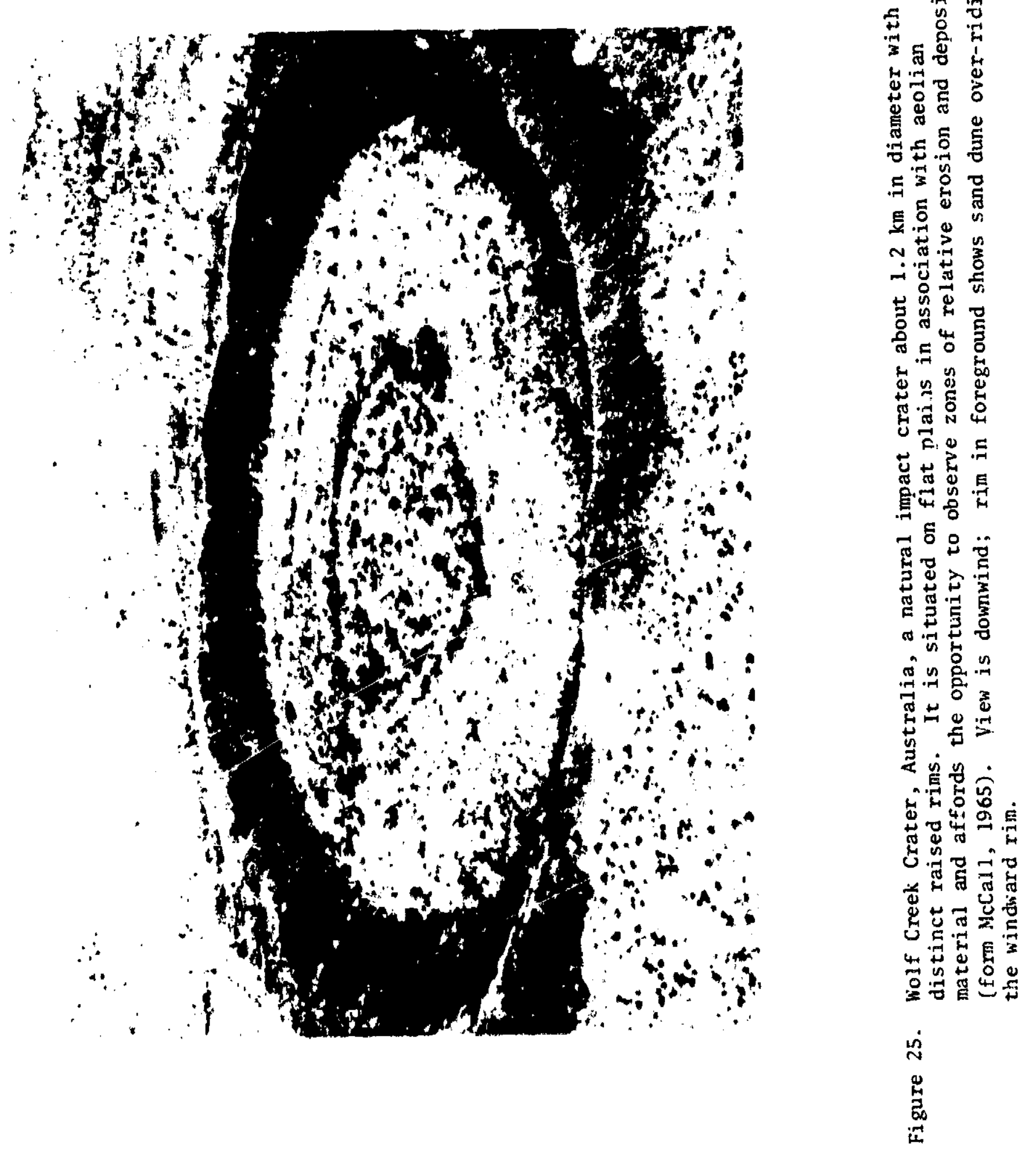

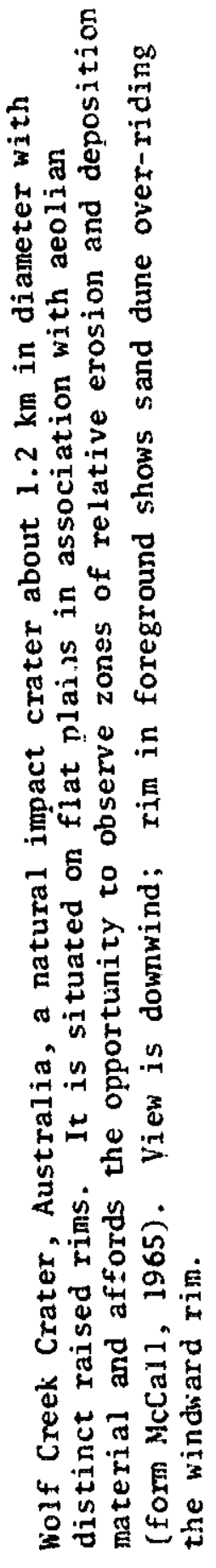




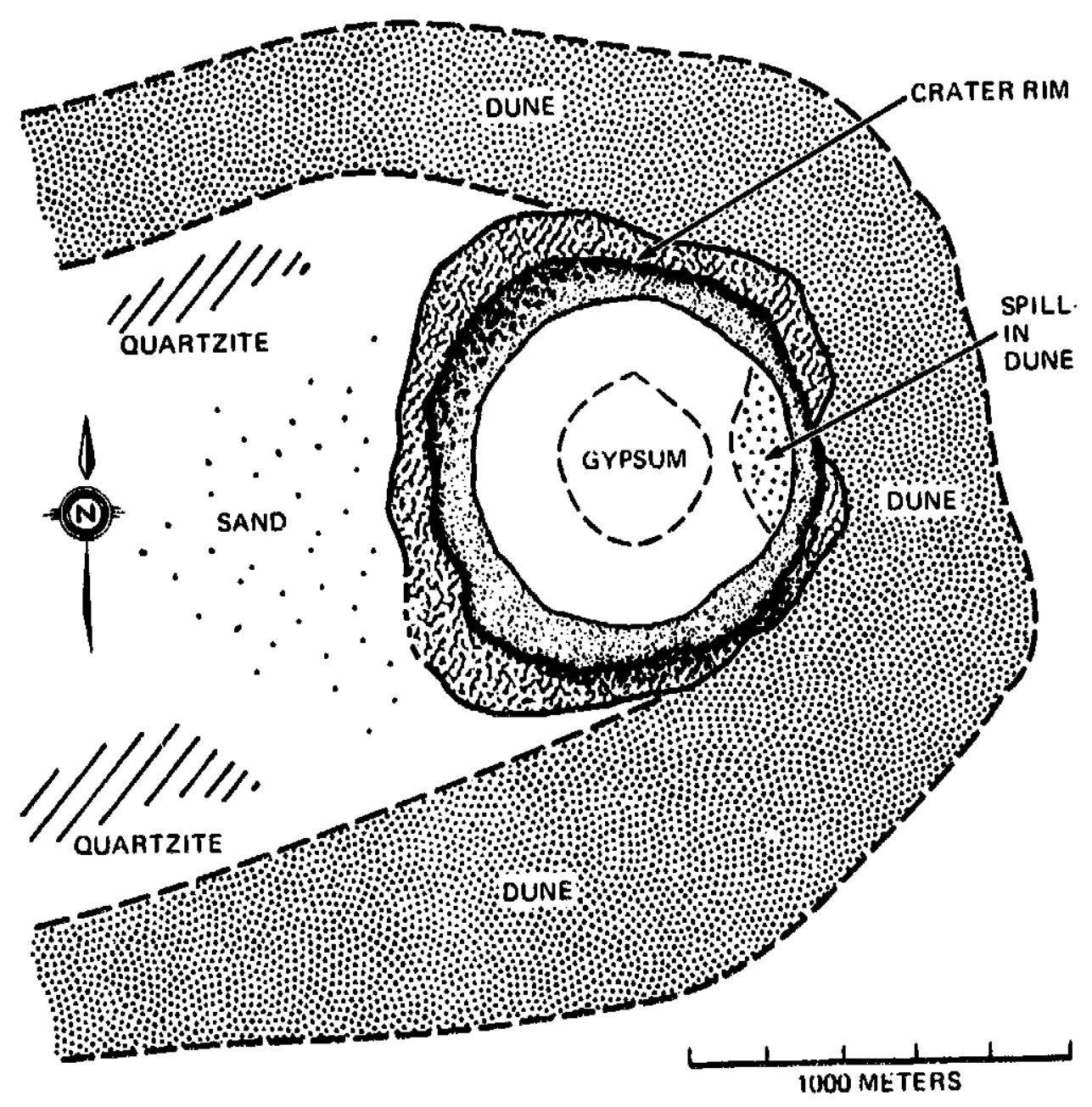

Figure 26. Geological sketch map of Wolf Creek impact crater (from McCall, 1965), showing approximate trilobate pattern of sand deposition a round the crater and zones of erosion indicated by hedrock
of quartzite. Wind is from right to left (east to west). 

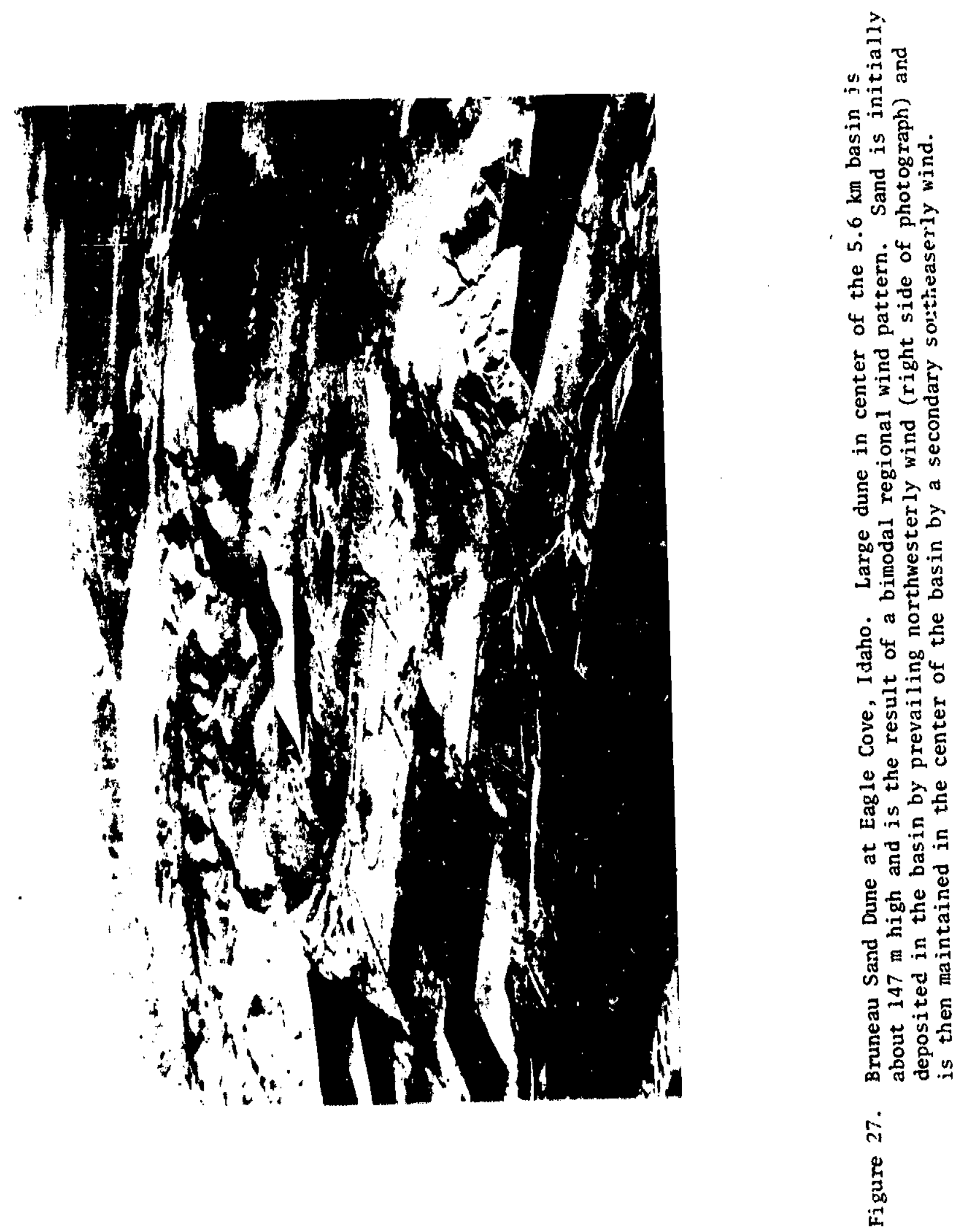